\title{
Preparation of immunostimulatory single-walled carbon nanotube/CpG DNA complexes and evaluation of their potential in cancer immunotherapy.
}

\section{$\operatorname{AUTHOR}(\mathrm{S})$ :}

Zhou, Shuwen; Hashida, Yasuhiko; Kawakami, Shigeru; Mihara, Junya; Umeyama, Tomokazu; Imahori, Hiroshi; Murakami, Tatsuya; Yamashita, Fumiyoshi; Hashida, Mitsuru

\section{CITATION:}

Zhou, Shuwen ...[et al]. Preparation of immunostimulatory single-walled carbon nanotube/CpG DNA complexes and evaluation of their potential in cancer immunotherapy.. International journal of pharmaceutics 2014, 471(1-2): 214-223

\section{ISSUE DATE:}

2014-08-25

\section{URL:}

http://hdl.handle.net/2433/189524

\section{RIGHT:}

(C) 2014 Elsevier B.V.; This is not the published version. Please cite only the published version.; この論文は出版社版でありません。引用の際に は出版社版をご確認ご利用ください。 
1

$8{ }^{1}$ Department of Drug Delivery Research, Graduate School of Pharmaceutical Sciences, Kyoto

9 University, Sakyo-ku, Kyoto 606-8501, Japan

$10{ }^{2}$ The Japan Society for the Promotion of Science (JSPS), Chiyoda-ku, Tokyo 102-8471, Japan

$11{ }^{3}$ Institute for Integrated Cell-Material Sciences (iCeMS), Kyoto University, Sakyo-ku, Kyoto

12 606-8501, Japan

$13{ }^{4}$ Department of Molecular Engineering, Graduate School of Engineering, Kyoto University,

14 Nishikyo-ku, Kyoto 615-8510, Japan

$15 *$ Corresponding authors

16 E-mail address: hashidam@pharm.kyoto-u.ac.jp (M. Hashida)

17 Tel: +81 75753 4545; Fax: +81 757539260 


\section{Abstract}

Carbon nanotubes (CNTs) have many interesting properties. In particular, their

3 photohyperthermic effect by near-infrared (NIR) irradiation could be used to kill cancer cells,

4 and could thus be applied in photohyperthermic therapy. However, the solubility of CNTs must

5 be improved before they can be used in biological applications. As DNA is reported to disperse

6 the CNTs in aqueous solution with $\pi-\pi$ interactions, we hypothesis that immunostimulatory CpG

7 DNA may also disperse the CNTs in aqueous solution. In this study, we used CpG DNA to

8 disperse single-walled CNTs (SWCNTs) in aqueous solution, in order to combine

9 photohyperthermic effect and immunoactivation together to achieve a more effective cancer

10 therapy. As expected, CpG DNA effectively dispersed the SWCNTs in aqueous solution via the

11 formation of SWCNT/CpG DNA complexes. Moreover, the immunoreactivity of the

12 SWCNT/CpG DNA complexes was investigated. The results showed that intratumoral

13 administration of the SWCNT/CpG DNA complexes in mice enhanced the production level of

14 inflammatory cytokines in tumor tissues. Finally, we evaluated the antitumor effects of the

15 SWCNT/CpG DNA complexes in tumor-bearing mice. The result indicated that intratumoral

16 administration of the SWCNT/CpG DNA complexes combined with NIR irradiation was a more

17 effective approach to prevent the proliferation of tumor growth.

19 Keywords: Carbon nanotubes, CpG DNA, immune activation, photohyperthermia, cancer 


\section{1. Introduction}

2 Carbon nanotubes (CNTs) consist exclusively of carbon atoms arranged in condensed

3 aromatic rings, which in turn are organized in one (single-walled carbon nanotube: SWCNT)

4 (Iijima and Ichihashi, 1993) or more (multi-walled carbon nanotube) (Iijima, 1991) concentric

5 graphene sheets rolled-up into cylinders. The diameters of the CNTs range from a few

6 nanometers to hundreds of nanometers. Owing to their unique structural and electronic

7 properties, CNTs have various possibilities for application in nanomedicine as biocompatible

8 materials for developing versatile drugs (Allen and Cullis, 2004; Bianco et al., 2005a), proteins

9 (Kam and Dai, 2005; Kam et al., 2004), genes (Cai et al., 2005; Liu et al., 2005), and vaccine

10 delivery systems (Panhuis, 2003). Especially, CNTs have a strong optical absorption in the near-

11 infrared (NIR) region and can release this energy within tissue to produce localized heating

12 (Chakravarty et al., 2008; Kam et al., 2005). Therefore, CNTs may be promising

13 photohyperthermic therapy agents for cancer therapy, because the selective thermal ablation of

14 malignant tissue is an important objective in cancer research and offers a viable alternative

15 treatment option when surgical resection is not possible (DeNardo GL and DeNardo SJ, 2008).

16 However, CNTs are completely insoluble in most organic solvents and aqueous buffers.

17 Indeed, since the time when CNTs were first produced, there has much interest, particularly in

18 the domain of biological and biomedical research, in enhancing the dispersibility and/or

19 solubility of CNTs in aqueous solution to overcome this important problem. It has been reported

20 that many detergents, such as sodium dodecyl benzene sulfonate and Triton-X100, are able to 
1 disperse CNTs, but these detergents are generally toxic to normal cells (Dong et al., 2009). To

2 resolve this problem, several approaches to functionalize CNTs, including defect-group

3 chemistry, covalent sidewall chemistry, non-covalent wrapping by polymers, biopolymers,

4 surfactants and other amphiphilic molecules, have been explored (Heister et al., 2010;

5 Mackiewicz et al., 2008; Shim and Ahn, 2012; Stranks et al., 2012; Tasis et al., 2006;). More

6 recently, Zheng et al. reported that DNA can disperse CNTs in aqueous solution, where the

7 aromatic nucleotide bases in DNA are suggested to interact with the CNTs through $\pi$ - $\pi$ stacking

8 (Hughes et al., 2007; Zheng et al., 2003a). Therefore, we considered that immunostimulatory

9 CpG DNA, which is capable of activating the immune system (Krieg, 2002), may be expected to

10 interact with CNTs to improve the dispersibility of the CNTs. Moreover, the immune responses

11 elicited by CpG DNA have the potential to inhibit tumor growth. In our previous studies, we

12 formulated complexes of phosphorothioate-type CpG DNA with cationic liposomes, and the

13 complexes showed strong immune responses and were effective in preventing proliferation of

14 cancer cells (Kuramoto et al., 2009, 2008; Zhou et al., 2012, 2010). Therefore, the combination

15 of photohyperthermic therapy and immunotherapy could be an effective approach for cancer 16 therapy.

17 In this study, we used CpG DNA to disperse SWCNTs via the formation of SWCNT/CpG

18 DNA complexes. It is suggested that these SWCNT/CpG DNA complexes may possess not only

19 a photohyperthermic effect, but also an immunostimulatory effect. First, we obtained the results 
1 that $\mathrm{CpG}$ DNA dispersed the SWCNTs in aqueous solution individually. Then, the

2 photohyperthermic effects of the SWCNT/CpG DNA complexes were observed in vitro and in

3 vivo with NIR laser irradiation. In addition, the SWCNT/CpG DNA complexes induced high

4 levels of inflammatory cytokine production in serum and in tumor tissues when intratumorally

5 administrated to colon 26 tumor-bearing mice. Furthermore, the SWCNT/CpG DNA complexes

6 when irradiated with NIR laser, significantly inhibited tumor growth in colon 26 tumor-bearing

7 mice. Thus, SWCNT/CpG DNA complexes with NIR laser irradiation would be an effective

8 approach in cancer immunotherapy. 


\section{2. Material and Methods}

\subsection{Oligonucleotides}

Oligonucleotides with phosphorothioate backbones were purchased from Operon (Tokyo,

4 Japan). The sequences of the oligonucleotides were 5'-

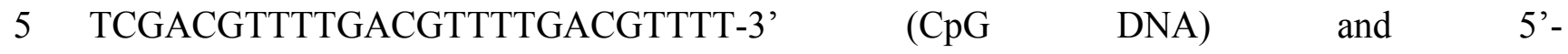

6 TGCAGCTTTtGAGCTTTTGAGCTTTT-3’ (GpC DNA).

\section{$7 \quad 2.2$ Cell lines}

8 Murine adenocarcinoma colon 26 tumor cells (Zhou et al., 2010) were grown in 5\% $\mathrm{CO}_{2}$ in

9 humidified air at $37^{\circ} \mathrm{C}$ with RPMI1640 medium (Nissui Pharmaceutical Co., Ltd., Tokyo, Japan)

10 supplemented with 10\% fetal bovine serum (MP Biomedicals, Inc., Irvine, CA, USA), $100 \mathrm{IU} / \mathrm{ml}$

11 penicillin, $100 \mu \mathrm{g} / \mathrm{ml}$ streptomycin, and $2 \mathrm{mM}$ L-glutamine.

\section{$12 \quad 2.3$ Animals}

13 Male BALB/c (5-week-old) mice were purchased from the Shizuoka Agricultural

14 Cooperative Association for Laboratory Animals (Shizuoka, Japan). All the animals were housed

15 with free access to food and water. The light (dark/light cycle was 12/12 h), temperature, and

16 humidity were kept constant throughout the experiments. All animal experiments were approved 
1 by the Animal Experimentation Committee of the Graduate School of Pharmaceutical Sciences,

2 Kyoto University.

\section{$3 \quad 2.4$ Preparation of SWCNT/CpG DNA complex}

4 One milligram of HiPco SWCNTs (containing 9 wt $\%$ of TGA Residue as Fe(iv) from the

5 manufacturer information, Carbon Nanotechnologies Incorporated) and $5 \mathrm{mg}$ of CpG DNA

6 (Operon, Tokyo, Japan) were sonicated in $5 \mathrm{ml}$ of $5 \%$ dextrose solution for 20 minutes in an ice-

7 water bath by the formation of complexes (SWCNT/CpG DNA complexes).

$8 \quad 2.5$ Evaluation of the amount of CpG DNA that's bound to the SWCNTs.

9 The amount of CpG DNA adsorbing to SWCNTs surface was determined by

10 spectrophotometically. The SWCNTs suspension complexed with CpG DNA was filtrated with

110.22 um centrifugal filter device (Ultrafree-MC, Merck Millipore, Darmstadt, Germany) to

12 remove free CpG DNA witch dose not bind to SWCNTs. Filtrated SWCNTs was resuspended

13 with distilled water, and optical absorbance spectrum was measured using Jasco V-670

14 spectrophotometer (Tokyo, Japan). The absorbance spectrum showed a peak at $260 \mathrm{~nm}$ and a

15 trough at $230 \mathrm{~nm}$ in UV region, which are characteristics of the absorbance of DNA. Then, the

16 amount of CpG DNA contained in SWCNTs suspension was calculated from the absorbance

17 difference between at $260 \mathrm{~nm}$ and at $230 \mathrm{~nm}$.

$18 \quad 2.6$ Evaluation of microscopic characterization of SWCNT/CpG DNA complex 
The SWCNT/CpG DNA complex was centrifuged for 155 minutes at 284,000 g to remove

2 any insoluble material. Then, the supernatant was filtered through a $30-\mathrm{kDa}$ molecular weight

3 filter (Amicon), and extensively washed several times with $5 \mathrm{ml}$ of $5 \%$ dextrose to remove any

4 unbound CpG DNA. The absorption spectra of the SWCNT/CpG DNA complex were analyzed

5 using a Perkin-Elmer Lambda $900 \mathrm{UV} / \mathrm{Vis} / \mathrm{NIR}$ spectrometer. Luminescence spectra of the

6 SWCNT/CpG DNA complex were analyzed using a SHIMADZU NIR-PL System. AFM images

7 were analyzed using an Asylum Technology MFP-3D-SA.

82.7 Temperature increase of SWCNT/CpG DNA complex solutions by NIR laser

9 irradiation

10 The SWCNT/CpG DNA complex was suspended at concentrations of $10 \mu \mathrm{g}$ of

$11 \mathrm{SWCNTs} / \mathrm{ml}$ or $20 \mu \mathrm{g}$ of SWCNTs/ml in 48 -well plates. Two hundred microliters of each

12 suspension was irradiated at $2 \mathrm{~W} / \mathrm{cm}^{2}$ or $3 \mathrm{~W} / \mathrm{cm}^{2}$ for 5 minutes by using an $808-\mathrm{nm}$ NIR laser

13 (Chameleon-RF, Coherent Japan Inc., Tokyo, Japan). The temperature was measured using a

14 thermocouple.

152.8 Evaluation of cancer cell ablation induced by SWCNT/CpG DNA complex with NIR 16 laser irradiation in vitro

17 The SWCNT/CpG DNA complex (1 $\mu \mathrm{g}$ of SWCNTs) or naked CpG DNA $(2 \mu \mathrm{g})$ were 18 added to colon 26 cells $\left(1 \times 10^{4}\right)$ and incubated for 24 hours. Then, the cells were washed three 
1 times with PBS, and exposed to $808 \mathrm{~nm}$ of NIR laser for 2 minutes at $5 \mathrm{~W} / \mathrm{cm}^{2}$. Cell death was

2 assessed using a Live-Dead-Cell Staining Kit (BioVision Inc., California, USA).

32.9 Evaluation of temperature increase and HSP70 production induced by SWCNT/CpG

4 DNA complex with NIR laser irradiation in vivo

5 Colon 26 cells $\left(3 \times 10^{5}\right)$ were transplanted into the flanks of mice ( $\mathrm{n}=5$ for each group). Once

6 the tumors reached a mean diameter of $5 \mathrm{~mm}, 5 \%$ of dextrose, naked CpG DNA $(10 \mu \mathrm{g})$, the

7 SWCNT/CpG DNA complex (1 $\mu \mathrm{g}$ of SWCNTs and $10 \mu \mathrm{g}$ of CpG DNA) or the SWCNT/GpC

8 DNA complex (1 $\mu \mathrm{g}$ of SWCNTs and $10 \mu \mathrm{g}$ of GpC DNA) were intratumorally injected into the

9 mice. Then, $5 \%$ of dextrose, naked CpG DNA $(10 \mu \mathrm{g})$ and the SWCNT/CpG DNA complex

10 treated groups were divided into NIR laser irradiated and non-NIR laser irradiated groups. For

11 the NIR laser irradiated groups, 24 hours after administration, the tumors were irradiated with

12 NIR laser 3 times of 30 s-on and 30 s-off once daily for 3 days. Tumor tissues were collected at

13 different time points and HSP70 production levels were measured using a HSP70 ELISA kit

14 (Enzo Life Sciences Inc., New York, USA). The temperature increase of the tumor tissues was

15 monitored using an InfReC Thermography R300 (NEC Avio Infrared Technologies Co., Ltd,

16 Tokyo, Japan) after NIR laser irradiation for $30 \mathrm{~s}$.

172.10 Evaluation of cytokine production in tumor tissues and serum after SWCNT/CpG

18 DNA complex intratumoral injection 
1 Colon 26 cells $\left(3 \times 10^{5}\right)$ were transplanted into the flanks of mice $(n=5$ for each group). Once

2 the tumors reached a mean diameter of $5 \mathrm{~mm}$, naked CpG DNA $(10 \mu \mathrm{g})$, the SWCNT/CpG DNA

3 complex $(1 \mu \mathrm{g}$ of SWCNTs and $10 \mu \mathrm{g}$ of CpG DNA) or the SWCNT/GpC DNA complex $(1 \mu \mathrm{g}$

4 of SWCNTs and $10 \mu \mathrm{g}$ of GpC DNA) were intratumorally injected into the mice. Then, 2 hours

5 later, tumor tissues and the serum were collected. Then, inflammatory cytokines including TNF-

$6 \alpha$, IL-12p70 and IL-6 productions were measured with a BD Cytometric Bead Array (CBA)

7 Mouse Inflammation Kit (Becton, Dickinson and Company, Tokyo, Japan) by using a BD

8 FACSCantoTM II Flow Cytometer (Becton, Dickinson and Company, Tokyo, Japan).

92.11 Evaluation of cytokine enhancement in tumor tissues induced by SWCNT/CpG DNA

10 complex after NIR laser irradiation

11 The SWCNT/CpG DNA complex (1 $\mu \mathrm{g}$ of SWCNTs and $10 \mu \mathrm{g}$ of CpG DNA) was

12 intratumorally injected into mice. Then, the SWCNT/CpG DNA complex treated mice were

13 divided into NIR laser irradiated and non-NIR laser-irradiated groups. For the NIR laser

14 irradiated groups, $24 \mathrm{~h}$ after administration, tumors were irradiated with NIR laser three times at

15 30-s-on and 30-s-off bursts once daily for 3 days. The tumor tissues were collected at 6 hours

16 after the last NIR laser irradiation and cytokines including TNF- $\alpha$, IL-12p70 and IL-6

17 productions were measured using a BD Cytometric Bead Array (CBA) Mouse Inflammation Kit.

182.12 Evaluation of antitumor effect by SWCNT/CpG DNA complex with NIR laser

19 irradiation 
1 Colon 26 cells $\left(3 \times 10^{5}\right)$ were transplanted into the flanks of mice. Once the tumors reached a

2 mean diameter of $5 \mathrm{~mm}$, naked CpG DNA $(10 \mu \mathrm{g})$, the SWCNT/CpG DNA complex $(1 \mu \mathrm{g}$ of

$3 \mathrm{CNT}$ and $10 \mu \mathrm{g}$ of CpG DNA), or the SWCNT/GpC DNA complex ( $1 \mu \mathrm{g}$ of CNT and $10 \mu \mathrm{g}$ of

4 GpC DNA) were intratumorally injected into the mice. Then, 24 hours later, NIR laser was

5 irradiated (30 s on and $30 \mathrm{~s}$ off for 3 times) for 3 days. The tumor sizes were measured up to 62

6 days after the transplantation of the colon 26 cells.

3. Results and Discussion

\subsection{Characterization of SWCNT/CpG DNA complexes}

CNTs have various possible applications in nanomedicine. However, such potential

11 biological applications of CNTs will require improvements to be made to the dispersibility

12 and/or solubility of CNTs in aqueous solution. Several papers have reported that wrapping of the

13 CNTs by DNA was found to be sequence-dependent (Zheng et al., 2003b), especially in the case

14 of Poly (T), which has the highest dispersion efficiency among fixed length homopolymers

15 (Zheng et al., 2003a). Other combinations of DNA sequence motifs such as $d(G T)_{n}$ or $d(A C)_{n}$

16 were also investigated (Vogel et al., 2007). However, the interaction of CNTs with CpG DNA is

17 less well studied. In this study, $1 \mathrm{mg}$ of HiPco SWCNTs and $5 \mathrm{mg}$ of CpG DNA were sonicated

18 in $5 \mathrm{ml}$ of $5 \%$ dextrose solution for 20 minutes in an ice-water bath to form SWCNT/CpG DNA

19 complexes. Microscopic characterizations of the resultant SWCNT/CpG DNA complexes were 
1 analyzed by UV/Visible-NIR absorption spectroscopy (Fig. 1a), photoluminescence

2 spectroscopy (Fig. 1b), and atomic force microscopy (AFM) (Fig. 1c). The SWCNT/CpG DNA

3 complexes were dispersed individually without the formation of remarkable aggregates, as

4 evidenced by the appearance of a high peak in the absorption spectra (Fig. 1a,). As the

5 photoluminescence isn't observed for aggregates but only for individualized SWCNTs, the strong

6 fluorescence in the photoluminescence spectra (Fig. 1b) indicated that well dispersed SWCNTs

7 were present. However, this result could not rule out the presence of some bundles. Meanwhile,

8 AFM images clearly showed that the SWCNT/CpG DNA complexes were well dispersed and

9 had a mean diameter of about 1-4 nm (Fig. 1c) and hight of about 0.5-2 nm (Fig. 1d). In addition,

10 removal of free DNA by a 30-kDa molecular weight filter did not cause SWCNT flocculation to

11 occur, and the resultant SWCNT/CpG DNA complexes were stable for months at $4{ }^{\circ} \mathrm{C}$. The

12 SWCNT/CpG DNA complexes were also redispersed in 5\% dextrose solution once freeze-dried,

13 indicating that the CpG DNA binding to the SWCNTs was very strong. Furthermore, the amount

14 of CpG DNA contained in SWCNTs suspension was calculated from the absorbance difference

15 between at $260 \mathrm{~nm}$ and at $230 \mathrm{~nm}$, and determined to be $1.27 \pm 0.24 \mathrm{ug} / 1 \mathrm{ug}$ SWCNTs. Taegar

16 and collaborators have reported that the best dispersion efficiency is achieved at DNA: CNT

17 ratios of 1:1 or 1:2 (Taegar et al., 2005). Our result was comparable with their result. The

18 fragmentation of $\mathrm{CpG}$ DNA was not achieved by sonication for 20 minutes (Fig. S1a). The

19 fragmentation of CpG DNA by sonication in the presence of SWCNTs was also checked. The

20 results were showed in Fig. S2b. The concentration of CpG DNA which by the sonication with 
1 SWCNTs were slightly decreased compared with CpG DNA that were not sonicated. However,

2 Large fragment of CpG DNA in SWCNT/CpG DNA complex were not detected. We considered

3 that during the preparation of SWCNT/CpG DNA complex, SWCNTs may have litter effect on

4 CpG DNA fragmentation. Moreover, in vitro studies showed that the sonicated CpG DNA

5 maintained an equivalent immunostimulatory potential to that of $\mathrm{CpG}$ DNA prior to sonication

6 (Fig. S1c). These results suggested that CpG DNA may still exhibit immunostimulatory activity

7 after sonication.

$8 \quad 3.2$ In vitro and in vivo photohyperthermic effects of SWCNT/CpG DNA complexes with

$9 \quad$ NIR irradiation

10 Supratim et al. recently demonstrated that DNA-encased CNTs are efficient for thermal

11 ablation (Ghosh et al., 2009). To investigate whether the SWCNT/CpG DNA complexes also

12 keep the photohyperthermic effect by NIR laser irradiation, the temperature increases achieved

13 following NIR laser irradiation of the SWCNT/CpG DNA complexes were evaluated. In Fig. 2,

14 when a SWCNT/CpG DNA complex solution was irradiated with a NIR laser at $3 \mathrm{~W} / \mathrm{cm}^{2}$ (Fig.

$15 \mathrm{2b}$ ), the temperature increased more rapidly than irradiation at $2 \mathrm{~W} / \mathrm{cm}^{2}$ (Fig. 2a). Additionally,

16 the increases in temperature of the SWCNT/CpG DNA complex solution were dependent on the

17 concentration of SWCNTs in solution and the NIR laser irradiation time. Moreover, the

18 photohyperthermic effect of the SWCNT/CpG DNA complexes was equal to the

19 photohyperthermic effect of SWCNT/GpC DNA complexes (in which the SWCNTs dispersed 
1 with GpC DNA exhibited no immunostimulatory effects), and SWCNT/Pluronic F-127 (in which

2 the SWCNTs were dispersed with the surfactant, Pluronic F127) (Fig. 2c). These results suggest

3 that the SWCNT/CpG DNA complexes also exhibit a thermal effect when irradiated with an NIR

4 laser, thereby highlighting their potential use for photohyperthermic therapy.

5 As the SWCNT/CpG DNA complexes released substantial vibrational energy after exposure

6 to NIR light, the use of NIR irradiation for the induction of hyperthermia is particularly attractive

7 because living tissues do not strongly absorb in this range (Weissleder, 2001). Therefore, a

8 number of biomedical investigations of CNTs have focused on their application for the treatment

9 of cancer (Liu et al., 2008a; Meng et al., 2008; Singh et al., 2005). In this study, the results of an

10 in vitro photohyperthermic ablation of the murine colorectal cancer cell line, colon 26 , treated

11 with the SWCNT/CpG DNA complex, using NIR irradiation, were evaluated with a Live-Dead-

12 Cell Kit. It was shown that most of the colon 26 cells treated with the SWCNT/CpG DNA

13 complex (1 $\mu \mathrm{g}$ of SWCNTs) were dead after NIR laser irradiation (Fig. 3f), as compared with the

14 same cells treated with the SWCNT/CpG DNA complex without NIR laser irradiation (Fig. 3e).

15 Meanwhile, the untreated (NT) cells (Fig. 3b) and naked CpG DNA treated cells (Fig. 3d)

16 survived even after receiving NIR laser irradiation. These results suggested that the

17 SWCNT/CpG DNA complex induced colon 26 cell cytotoxicity after NIR laser irradiation.

18 Moreover, we also investigated the photohyperthermic effects of the SWCNT/CpG DNA

19 complex in vivo by evaluating the temperature increases and the production of HSP70 in tumor 
1 tissue after NIR laser irradiation. HSPs are induced by elevated temperatures (typically in excess

2 of $43{ }^{\circ} \mathrm{C}$ ) and serve as endogenous cellular markers of thermal stress (Burke et al., 2009). As

3 seen in Fig. 4a, after $30 \mathrm{~s}$ of NIR laser irradiation, the temperature of the tumor tissues treated

4 with the SWCNT/CpG DNA complex or the SWCNT/GpC DNA (not immunostimulatory)

5 complex were increased approximately up to $43{ }^{\circ} \mathrm{C}$. On the other hand, the temperature of the

6 tumor tissues treated with 5\% dextrose or naked CpG DNA remained the same as the

7 temperature before NIR laser irradiation. Then, we evaluated the production of HSP70 in tumor

8 tissue after NIR laser irradiation. As shown in Fig. 4b, HSP70 production in the tumor tissues of

9 mice treated with the SWCNT/CpG DNA complex + NIR were significantly higher than that in

10 mice treated only with the SWCNT/CpG DNA complex at 6 hours after NIR laser irradiation (P

$11<0.01)$. In addition, in the tumor treated with the SWCNT/GpC DNA complex + NIR laser, the

12 HSP70 production was induced to a high level (Fig. 4c). In contrast, the HSP70 production in

13 mice treated with 5\% dextrose or naked CpG DNA was of a comparable level to that in the mice

14 that did not receive NIR laser irradiation (Fig. 4c). These results suggest that both SWCNT

15 complexes when stimulated with NIR laser irradiation increased the temperature in the tumor

16 tissue and induced the enhancement of HSP70 production.

\section{3.3 Immune effect of SWCNT/CpG DNA complexes in tumor-bearing mice}

18 CpG DNA can be taken up by macrophages and dendritic cells, leading to the production of

19 Th1-type cytokines such as IFN- $\gamma$ (Krieg, 2002). In our previous studies, we have demonstrated 
1 that CpG DNA Lipoplex showed strong immune responses and were effective in preventing

2 proliferation of cancer cells (Kuramoto et al., 2009, 2008; Zhou et al., 2012, 2010). Therefore,

3 using CpG DNA to disperse the SWCNTs may lead to complexes having an immunostimulatory

4 effect. In this study, the immunoreactivity of the SWCNT/CpG DNA complex was evaluated by

5 measuring the production of inflammatory cytokines in serum and in the tumor tissues in colon

626 bearing mice at different time points (Fig. S3-S4). After intratumoral injection of the

7 SWCNT/CpG DNA complex, the production of TNF- $\alpha$ and IL-6 in the serum and the tumor

8 tissues showed a peak value at 2 hours after administration (Fig. S3a, S3b, S4a and S4b). The

9 production of IL-12p70 showed a peak value in the serum at 8 hours after administration (Fig.

$10 \mathrm{~S} 3 \mathrm{c}$ ) and in the tumor tissues at 2 hours after administration (Fig. S4c).

11 In addition, compared with untreated mice or mice injected with naked CpG DNA or the

12 SWCNT/GpC DNA complex, mice injected with the SWCNT/CpG DNA complex significantly

13 induced higher levels of TNF- $\alpha$ and IL-6 production both in serum (Fig. 5a and 5b) and in tumor

14 tissue (Fig.6a and 6b) at 2 hours after injection. The SWCNT/CpG DNA complex also induced

15 higher levels of IL-12p70 production in tumor tissues than compared with either naked CpG

16 DNA or the SWCNT/GpC DNA complex (Fig. 5c). These results demonstrated that the

17 SWCNT/CpG DNA complex induced TNF- $\alpha$ and IL-6 cytokine production in tumor tissues and

18 in serum, and may have the potential to inhibit tumor growth. As several papers have already

19 demonstrated that CNTs are able to enter immune cells such as macrophages actively and 
1 passively via incomplete phagocytosis or by impaling the membrane (Cheng et al., 2009; Kam et

2 al., 2005; Kraszewski et al., 2012), we considered that the SWCNT/CpG DNA complex may be

3 more effectively recognized by the immune cells than naked CpG DNA. Moreover, our results

4 suggest that the SWCNT/CpG DNA complex induced higher levels of cytokine production than

5 naked CpG DNA, thereby confirming the reports that functionalized CNTs could enhance CpG

6 DNA uptake and their immunostimulatory properties (Bianco et al., 2005b; Zhao et al., 2011).

7 Furthermore, Fan et al. also has reproted that functionalized carbon nanotubes that conjugated

8 with CpG DNA enhanced activity of CpG DNA and was effective for both brain and systemic

9 melanomas (Fan et al., 2012).

10 As some reports have shown that the photohyperthermic effect could enhance immune

11 responses in vivo (Zhang et al., 2008; Gastpar et al., 2005), next, we investigated the immune

12 effects of the SWCNT/CpG DNA complex after NIR laser irradiation. The results showed that

13 there was no significant difference between the cytokine production levels of the SWCNT/CpG

14 DNA complex and the SWCNT/CpG DNA complex + NIR laser irradiation (data not shown).

15 This result may be because the photohyperthermic effects induced by the SWCNT/CpG DNA

16 complex + NIR were either not enough to enhance the immune response, or the enhanced

17 immune response was too low to be detected. We will investigate these details in the future.

18 3.4 Enhancement of anti-tumor effect by SWCNT/CpG DNA complexes after NIR laser

19 irradiation 
Then, the antitumor effect of the SWCNT/CpG DNA complex was also evaluated in tumor-

2 bearing mice. For this study, $3 \times 10^{5}$ colon 26 cells were subcutaneously injected into the flanks of

3 the tumor-bearing mice. Once the tumor volumes reached approximately $200 \mathrm{~mm}^{3}$, the mice

4 were injected intratumorally with $50 \mu$ of treatment solution, which contained $10 \mu \mathrm{g}$ of either

5 naked CpG DNA, the SWCNT/CpG DNA complex (1 $\mu \mathrm{g}$ of SWCNTs and $10 \mu \mathrm{g}$ of CpG DNA)

6 or the SWCNT/GpC DNA complex, which are not immunostimulatory $(1 \mu \mathrm{g}$ of SWCNTs and 10

$7 \mu \mathrm{g}$ of GpC DNA). ( $=6$ per group). It was found that there was no statistical differences among

8 the group mean tumor volumes of the three solutions tested at the onset of treatment. After

9 treatment, compared with the untreated (NT), the NIR laser-only, and the SWCNT/GpC DNA

10 complex + NIR studies, the tumor volumes of the SWCNT/CpG DNA complex + NIR treated

11 mice had decreased significantly by day $24(\mathrm{P}<0.001$ compared with the NT and NIR laser -

12 only; $\mathrm{P}<0.01$ compared with the SWCNT/GpC DNA complex + NIR) and by day $26(\mathrm{P}<0.001$

13 compared with NT; $\mathrm{P}<0.01$ compared with NIR laser - only; $\mathrm{P}<0.05$ compared with the

14 SWCNT/GpC DNA complex + NIR) after tumor cell implantation (Fig. 7). Moreover, the

15 SWCNT/CpG DNA complex + NIR treated mice were even significantly decreased compared

16 with naked $\mathrm{CpG}$ DNA or naked $\mathrm{CpG}$ DNA + NIR treated mice $(\mathrm{P}<0.05)$ (Fig. 7). The tumor

17 volumes of the SWCNT/CpG DNA complex + NIR treated mice were smaller than that of the

18 SWCNT/CpG DNA complex treated mice, albeit a minor difference. These results demonstrated

19 that the combination of SWCNT/CpG DNA complex administration and NIR laser irradiation 
1 led to a more efficient antitumor effect than compared with that achieved by naked CpG DNA

2 administration or SWCNT/GpC DNA complex administration.

3 Several papers have reported that CNTs are effective in photohyperthermic therapy (Burke

4 et al., 2009; Ghosh et al., 2009; Xiao et al., 2009). An advantage of NIR is that biological

5 systems largely lack chromophores that absorb in this region, and as such, the NIR light should

6 effectively and safely penetrate normal tissue and ablate any cells to which the CNTs are

7 attached. Moreover, hyperthermic therapy has been clinically used in the management of solid

8 tumors because it can synergistically enhance tumor cytotoxicity when combined with

9 chemotherapy or radiotherapy (Falk and Issels, 2001; Wust et al., 2002). However, the

10 combination of immunotherapy with CNTs is less well studied. In the present study, we

11 successfully combined the photohyperthermic effects and immune effects together using the

12 SWCNT/CpG DNA complex, and observed the resultant antitumor effect in vivo (Fig. 7). In

13 practice, the toxicology of SWCNTs also needs to be addressed prior to using them in clinical

14 situations. It has been found that well-functionalized CNTs, which are stable in physiological

15 environments, are non-toxic to cells in vitro and non-toxic to mice in vivo (Liu et al., 2009; Liu

16 et al., 2008; Schipper et al., 2008; Yang et al., 2008). Furthermore, Kagan et al. recently showed

17 that hypochlorite and reactive radical intermediates of the human neutrophil enzyme,

18 myeloperoxidase, enhance the biodegradation of SWCNTs in vitro, in neutrophils, and to a lesser 
1 degree, in macrophages (Kagan et al., 2010). Therefore, the SWCNT/CpG DNA complex may

2 be applied for effective cancer immunotherapy without significant toxicity.

\section{4. Conclusions}

4 We successfully prepared the SWCNTs / CpG DNA complexes, which were dispersed well

5 and possessed both the photohyperthemic effects and the immune effects. The SWCNTs / CpG

6 DNA complexes enhanced the production level of inflammatory cytokines in tumor tissues when

7 intratumoral administration. We also have shown an effective combination cancer therapy using

8 SWCNTs / CpG DNA complexes in mice. Intratumoral administration of SWCNTs / CpG DNA

9 complexes with NIR irradiation prevented the proliferation of tumor growth in mice and

10 prolonged the survival time of mice. These were suggested that combination of

11 photohyperthermic therapy and immunotherapy would be an effective approach in cancer

12 therapy. 


\section{Acknowledgments}

2 This work was supported in part by a Grant-in-Aid for Scientific Research (A) (23240072) and

3 by a fellowship grant from the Japan Society for the Promotion of Sciences $(23 \cdot 2743)$.

4 


\section{$1 \quad$ References}

2 Allen, T.M., Cullis, P.R., 2004. Drug delivery system: Entering the mainstream. Science. 303,

$3 \quad 1818-1822$.

4 Bianco, A., Kostarelos, K., Partidos, C.D., Prato, M., 2005a. Biomedical applications of

5 functionalised carbon nanotubes. Chem. Commun. 5, 571-577.

6 Bianco, A., Hoebeke, J., Godefroy, S., Chaloin, O., Pantarotto, D., Briand, J.P., Muller, S., Prato,

7 M., Partidos, C.D., 2005b. Cationic carbon nanotubes bind to $\mathrm{CpG}$ oligodeoxynucleotides and

8 enhance their immunostimulatory properties. J. Am. Chem. Soc. 127, 58-59.

9 Burke, A., Ding, X., Singh, R., Kraft, R.A., Levi-Polyachenko, N., Rylander, M.N., Szot, C.,

10 Buchanan, C., Whitney, J., Fisher, J., Hatcher, H.C., D'Agostino, R. Jr., Kock, N.D., Ajayan,

11 P.M., Carroll, D.L., Akman, S., Torti, F.M., Torti, S.V., 2009. Long-term survival following a

12 single treatment of kidney tumors with multiwalled carbon nanotubes and near-infrared radiation.

13 Proc. Natl. Acad. Sci. U. S. A. 106, 12897-12902.

14 Cai, D., Mataraza, J.M., Qin, Z.H., Huang, Z., Huang, J., Chiles, T.C., Carnahan, D., Kempa, K.,

15 Ren, Z., 2005. Highly efficient molecular delivery into mammalian cells using carbon nanotube

16 spearing. Nature. Meth. 2, 449-454. 
1 Cheng, C., Muller, K.H., Koziol, K.K.K., Skepper, J.N., Midgley, P.A., Welland, M.E., Porter,

2 A.E., 2009. Toxicity and imaging of multi-walled carbon nanotubes in human macrophage cells.

3 Biomaterials. 30, 4152-4160.

4 DeNardo, G.L., DeNardo, S.J., 2008. Update: Turning the heat on cancer. Cancer Biother.

5 Radiopharm. 23, 671-680.

6 Dong, L., Witkowski, C.M., Craig, M.M., Greenwade, M.M., Joseph, K.L., 2009. Cytotoxicity

7 effects of different surfactant molecules conjugated to carbon nanotubes on human astrocytoma

8 cells. Nanoscale. Res. Lett. 4, 1517-1523.

9 Fan, H., Zhang, I., Chen, X., Zhang, L., Wang, H., Da Fonseca, A., Manuel, E.R., Diamond, D.J.,

10 Raubitschek, A., Badie, B., 2012. Intracerebral CpG immunotherapy with carbon nanotubes

11 abrogates growth of subcutaneous melanomas in mice. Clin. Cancer. Res. 18, 5628-5638.

12 Falk, M.H., Issels, R.D., 2001. Hyperthermia in oncology. Int. J. Hyperthermia. 17, 1-18.

13 Gastpar, R., Gehrmann, M., Bausero, M.A., Asea, A., Gross, C., Schroeder, J.A., Multhoff, G.,

14 2005. Heat shock protein 70 surface-positive tumor exosomes stimulate migratory and cytolytic

15 activity of natural killer cells. Cancer. Res. 65, 5238-5247. 
1 Ghosh, S., Dutta, S., Gomes, E., Carroll, D., D'Agostino, Jr. R., Olson, J., Guthold, M., Gmeiner,

2 W.H., 2009. Increased Heating Efficiency and Selective Thermal Ablation of Malignant Tissue

3 with DNA-Encased Multiwalled Carbon Nanotubes. ACS. Nano. 3, 2667-2673.

4 Heister, E., Lamprecht, C., Neves, V., Tîlmaciu, C., Datas, L., Flahaut, E., Soula, B.,

5 Hinterdorfer, P., Coley, H.M., Silva, S.R., McFadden, J., 2010. Higher dispersion efficacy of

6 functionalized carbon nanotubes in chemical and biological environments. ACS. Nano. 4, 2615-

72626.

8 Hughes, M.E., Brandin, E., Golovchenko, J.A., 2007. Optical absorption of DNA-carbon

9 nanotube structures. Nano. Lett. 7, 1191-1194.

10 Iijima, S., 1991. Helical microtubules of graphitic carbon. Nature. 354, 56-58.

11 Iijima, S., Ichihashi, T., 1993. Single-shell carbon nanotubes of 1-nm diameter. Nature. 363, $12 \quad 603-605$.

13 Kagan, V.E., Konduru, N.V., Feng, W., Allen, B.L., Conroy, J., Volkov, Y., Vlasova, II.,

14 Belikova, N.A., Yanamala, N., Kapralov, A., Tyurina, Y.Y., Shi, J., Kisin, E.R., Murray, A.R.,

15 Franks, J., Stolz, D., Gou, P., Klein-Seetharaman, J., Fadeel, B., Star, A., Shvedova, A.A., 2010.

16 Carbon nanotubes degraded by neutrophil myeloperoxidase induce less pulmonary inflammation.

17 Nat. Nanotechnol. 5, 354-359. 
1 Kam, N.W., O'Connell, M., Wisdom, J.A., Dai, H., 2005. Carbon nanotubes as multifunctional

2 biological transporters and near-infrared agents for selective cancer cell destruction. Proc. Natl.

3 Acad. Sci. U. S. A. 102, 11600-11605.

4 Kam, N.W.S., Dai, H.J., 2005. Carbon nanotubes as intracellular protein transporters: Generality

5 and biological functionality. J. Am. Chem. Soc. 127, 6021-6026.

6 Kam, N.W.S., Jessop, T.C., Wender, P.A., Dai, H.J., 2004. Nanotube molecular transporters:

7 Internalization of carbon nanotube-protein conjugates into mammalian cells. J. Am. Chem. Soc.

$8 \quad 126,6850-6851$.

9 Kraszewski, S., Bianco, A., Tarek, M., Ramseyer, C., 2012. Insertion of short amino-

10 functionalized single-walled carbon nanotubes into phospholipid bilayer occurs by passive

11 diffusion. PLoS. One. 7, 40703-40714.

12 Krieg, A.M., 2002. CpG motifs in bacterial DNA and their immune effects. Annu. Rev. Immunol.

$1320,709-760$.

14 Kuramoto, Y., Kawakami, S., Zhou, S., Fukuda, K., Yamashita, F., Hashida, M., 2009.

15 Mannosylated cationic liposomes/CpG DNA complex for the treatment of hepatic metastasis

16 after intravenous administration in mice. J. Pharm. Sci. 98, 1193-1197. 
1 Kuramoto, Y., Kawakami, S., Zhou, S., Fukuda, K., Yamashita, F., Hashida, M., 2008. Efficient

2 peritoneal dissemination treatment obtained by an immunostimulatory phosphorothioate-type

3 CpG DNA/cationic liposome complex in mice. J. Control. Release. 126, 274-280.

4 Liu, Y., Wu, D.C., Zhang, W.D., Jiang, X., He, C.B., Chun, T.S., Goh, S.H., Leong, K.W., 2005.

5 Polyethylenimine-grafted multi-walled carbon nanotubes for secure noncovalent immobilization

6 and efficient delivery of DNA. Angew. Chem. Int. Ed. 44, 4782-4785.

7 Liu, Z., Chen, K., Davis, C., Sherlock, S., Cao, Q., Chen, X., Dai, H., 2008a. Drug delivery with

8 carbon nanotubes for in vivo cancer treatment. Cancer. Res. 68, 6652-6660.

9 Liu, Z., Davis, C., Cai, W., He, L., Chen, X., Dai, H., 2008b. Circulation and long-term fate of

10 functionalized, biocompatible single-walled carbon nanotubes in mice probed by Raman

11 spectroscopy. Proc. Natl. Acad. Sci. U. S. A. 105, 1410-1415.

12 Liu, Z., Tabakman, S., Welsher, K., Dai, H., 2009. Carbon nanotubes in biology and medicine: in

13 vitro and in vivo detection, imaging and drug delivery. Nano. Res. 2, 85-120.

14 Mackiewicz, N., Surendran, G., Remita, H., Keita, B., Zhang, G., Nadjo, L., Hagège, A., Doris,

15 E., Mioskowski, C., 2008. Supramolecular self-assembly of amphiphiles on carbon nanotubes: a

16 versatile strategy for the construction of $\mathrm{CNT} / \mathrm{metal}$ nanohybrids, application to electrocatalysis.

17 J. Am. Chem. Soc. 130, 8110-8111. 
1 Meng, J., Meng, J., Duan, J., Kong, H., Li, L., Wang, C., Xie, S., Chen, S., Gu, N., Xu, H., Yang,

2 X.D., 2008. Carbon nanotubes conjugated to tumor lysate protein enhance the efficacy of an

3 antitumor immunotherapy. Small. 4, 1364-1370.

4 Panhuis, M.I.H.,2003. Vaccine delivery by carbon nanotubes. Chem. Biol. 10, 898-899.

5 Chakravarty, P., Marches, R., Zimmerman, N.S., Swafford, A.D., Bajaj, P., Musselman, I.H.,

6 Pantano, P., Draper, R.K., Vitetta, E.S., 2008. Thermal Ablation of Tumor Cells with Antibody-

7 Functionalized Single-Walled Carbon Nanotubes. Proc. Natl. Acad. Sci. U.S.A. 105, 8697-8702.

8 Schipper, M.L., Nakayama-Ratchford, N., Davis, C.R., Kam, N.W.S., Chu, P., Liu, Z., Sun, X.,

9 Dai, H., Gambhir, S., 2008. A pilot toxicology study of single-walled carbon nanotubes in a

10 small sample of mice. Nat. Nanotechnol. 3, 216-221.

11 Shim, J.S., Ahn, C.H., 2012. Optical immunosensor using carbon nanotubes coated with a

12 photovoltaic polymer. Biosens. Bioelectron. 34, 208-214.

13 Singh, R., Pantarotto, D., McCarthy, D., Chaloin, O., Hoebeke, J., Partidos, C.D., Briand, J.P.,

14 Prato, M., Bianco, A., Kostarelos, K., 2005. Binding and condensation of plasmid DNA onto

15 functionalized carbon nanotubes: Toward the construction of nanotube-based gene delivery

16 vectors. J. Am. Chem. Soc. 127, 4388-4396. 
1 Stranks, S.D., Yong, C.K., Alexander-Webber, J.A., Weisspfennig, C., Johnston, M.B., Herz,

2 L.M., Nicholas, R.J., 2012. Nanoengineering coaxial carbon nanotube-dual-polymer

3 heterostructures. ACS. Nano. 6, 6058-6066.

4 Taeger, S., Xuang, L.Y., Gunther, K., Mertig, M., 2005. Noncovalent sidewall functionalization

5 of carbon nanotubes by biomolecules: single-stranded DNA and hydrophobin. AIP Conf. Proc.

$6 \quad 262-265$.

7 Tasis, D., Tagmatarchis, N., Bianco, A., Prato, M., 2006. Chemistry of carbon nanotubes. Chem.

8 Rev. 106, 1105-1136.

9 Vogel, S.R., Kappes, M.M., Hennrich, F., Richert, C., 2007. An unexpected new optimum in the

10 structure space of DNA solubilizing single-walled carbon nanotubes. Chemistry. 13, 1815-1820.

11 Weissleder, R., 2001. A clearer vision for in vivo imaging. Nat. Biotechnol. 19, 316-317.

12 Wust, P., Hildebrandt, B., Sreenivasa, G., Rau, B., Gellermann, J., Riess, H., Felix, R., Schlag, P.,

13 2002. Hyperthermia in combined treatment of cancer. Lancet. Oncol. 3, 487-497.

14 Xiao, Y., Gao, X., Taratula, O., Treado, S., Urbas, A., Holbrook, R.D., Cavicchi, R.E., Avedisian,

15 C.T., Mitra, S., Savla, R., Wagner, P.D., Srivastava, S., He, H., 2009. Anti-HER2 IgY antibody-

16 functionalized single-walled carbon nanotubes for detection and selective destruction of breast

17 cancer cells. BMC. Cancer. 9, 351-362. 
1 Yang, S.T., Wang, X., Jia, G., Gu, Y., Wang, T., Nie, H., Ge, C., Wang, H., Liu, Y., 2008. Long-

2 term accumulation and low toxicity of single-walled carbon nanotubes in intravenously exposed

3 mice. Toxicol. Lett. 101, 181-182.

4 Zhang, H.G., Mehta, K., Cohen, P., Guha, C., 2008. Hyperthermia on immune regulation: a

5 temperature's story. Cancer. Lett. 271, 191-204.

6 Zhao, D., Alizadeh, D., Zhang, L., Liu, W., Farrukh, O., Manuel, E., Diamond, D.J., Badie, B.,

7 2011. Carbon nanotubes enhance $\mathrm{CpG}$ uptake and potentiate antiglioma immunity. Clin. Cancer.

8 Res. 17, 771-782.

9 Zheng, M., Jagota, A., Semke, E.D., Diner, B.A., McLean, R.S., Lustig, S.R., Richardson, R.E.,

10 Tassi, N.G., 2003a. DNA-assisted dispersion and separation of carbon nanotubes. Nat. Mater. 2,

$11338-342$.

12 Zheng, M., Jagota, A., Strano, M.S., Santos, A.P., Barone, P., Chou, S.G., Diner, B.A.,

13 Dresselhaus, M.S., McLean, R.S., Onoa, G.B., Samsonidze, G.G., Semke, E.D., Usrey, M.,

14 Walls, D.J., 2003b. Structure-based carbon nanotube sorting by sequence-dependent DNA

15 assembly. Science. 302, 1545-1548.

16 Zhou, S., Kawakami, S., Higuchi, Y., Yamashita, F., Hashida, M., 2012. The involvement of NK

17 cell activation following intranasal administration of CpG DNA lipoplex in the prevention of

18 pulmonary metastasis and peritoneal dissemination in mice. Clin. Exp. Metastasis. 29, 63-70. 
1 Zhou, S., Kawakami, S., Yamashita, F., Hashida, M., 2010. Intranasal administration of CpG

2 DNA lipoplex prevents pulmonary metastasis in mice. Cancer. Lett. 287, 75-81. 


\section{FIGURES}

3 Figure 1. Characterization of the SWCNT/CpG DNA complex. (a) UV-Vis-NIR absorption

4 spectra of the SWCNT/CpG DNA complex. (b) Photoluminescence maps of the SWCNT/CpG

5 DNA complex. (c) AFM images of the SWCNT/CpG DNA complex. (d) Height of

6 SWCNT/CpG DNA complex in AFM images. Results are representative of three experiments.

7 Figure 2. Temperature increases of the SWCNT/CpG DNA complex through NIR laser

8 irradiation. SWCNT/CpG DNA complex solutions were prepared at two concentrations $(10 \mu \mathrm{g}$

$9 \mathrm{CNT} / \mathrm{ml}$ and $20 \mu \mathrm{g} \mathrm{CNT} / \mathrm{ml}$ ) and placed in 48-well plates. Each sample was then irradiated with

10 an 808-nm NIR laser at a different power level-(a) power level $2 \mathrm{~W} / \mathrm{cm}^{2}$, (b) power level

$113 \mathrm{~W} / \mathrm{cm}^{2}$ - for 5 minutes. The temperatures were measured every $20 \mathrm{~s}$. (c) Temperature increases

12 of the SWCNT/CpG DNA complex, the SWCNT/GpC DNA complex, and the SWCNT /F-127

13 after NIR laser irradiation. Results are representative of three experiments.

14 Figure 3. In vitro photohyperthermic effects of the SWCNT/CpG DNA complex. The viabilities

15 of colon 26 cells treated with naked CpG DNA or the SWCNT/CpG DNA complex following

16 NIR laser irradiation were examined using a Live-Dead-Cell Kit. The representative images from

17 each sample are shown. Cells with green fluorescence were considered alive, whereas those with

18 red fluorescence were dead. (a) Untreated colon 26 cells. (b) Untreated colon 26 cells + NIR

19 laser. (c) Colon 26 cells treated with CpG DNA alone. (d) Colon 26 cells treated with CpG DNA 
$1+$ NIR. (e) Colon 26 cells treated with the SWCNT/CpG DNA complex. (f) Colon 26 cells

2 treated with the SWCNT/CpG DNA complex + NIR. Results are representative of more than

3 three experiments.

4 Figure 4. Temperature increases and HSP70 production induced by NIR laser irradiation of the

5 SWCNT/CpG DNA complex in vivo. (a) Temperature increases in tumor tissues after NIR laser

6 irradiation. (b) HSP70 production induced by NIR laser irradiation of the SWCNT/CpG DNA

7 complex in tumor tissues at different time points. * $\mathrm{P}<0.05$ compared with SWCNT/CpG DNA

8 complex + NIR at 2 hours after NIR laser irradiation. ${ }^{* *} \mathrm{P}<0.01$ compared with SWCNT/CpG

9 DNA complex at 6 hours, and SWCNT/CpG DNA complex + NIR at 24 hours after NIR laser

10 irradiation. (c) HSP70 production induced by NIR laser irradiation of 5\% dextrose, naked CpG

11 DNA, the SWCNT/CpG DNA complex or the SWCNT/GpC DNA complex in tumor tissue at 6

12 hours after NIR laser irradiation. * $\mathrm{P}<0.05$ compared with $5 \%$ dextrose and the SWCNT/CpG

13 DNA complex; ** $\mathrm{P}<0.01$ compared with $5 \%$ dextrose + NIR and naked CpG DNA + NIR. \# P

$14<0.05$ compared with 5\% dextrose + NIR, naked CpG DNA + NIR, and the SWCNT/CpG DNA

15 complex. Each value represents the mean + S. D. $(n=5)$. Results are representative of three

16 experiments.

17 Figure 5. Cytokine productions induced by the SWCNT/CpG DNA complex in tumor tissue. (a)

18 TNF- $\alpha$ production levels in tumor tissues after naked CpG DNA, SWCNT/CpG DNA complex

19 or SWCNT/GpC DNA complex administration. $* \mathrm{P}<0.05$ compared with NT and SWCNT/GpC 
1 DNA complex. (b) IL-6 production levels in tumor tissues after naked CpG DNA, SWCNT/CpG

2 DNA complex or SWCNT/GpC DNA complex administration. * $\mathrm{P}<0.05$ compared with naked

3 CpG DNA; ** $\mathrm{P}<0.01$ compared with NT and the SWCNT/GpC DNA complex. (c) IL-12p70

4 production levels in tumor tissues after naked CpG DNA, SWCNT/CpG DNA complex or

5 SWCNT/GpC DNA complex administration. Each value represents the mean + S. D. $(n=5-6)$.

6 Results are representative of more than three experiments.

8 Figure 6. Cytokine productions induced by the SWCNT/CpG DNA complex in serum. (a) TNF-

$9 \alpha$ production levels in serum after naked CpG DNA, SWCNT/CpG DNA complex or

10 SWCNT/GpC DNA complex administration. * $\mathrm{P}<0.05$ compared with NT and the

11 SWCNT/GpC DNA complex. (b) IL-6 production levels in serum after naked CpG DNA,

12 SWCNT/CpG DNA complex or SWCNT/GpC DNA complex administration. ** $\mathrm{P}<0.01$

13 compared with NT, naked CpG DNA and the SWCNT/GpC DNA complex. Each value

14 represents the mean + S. D. $(n=5-6)$. Results are representative of more than three experiments.

16 Figure 7. Tumor volume of mice after combination of SWCNT/CpG DNA complex intratumoral

17 administration and NIR laser irradiation. \# $\mathrm{P}<0.05$ compared with naked CpG DNA and naked

18 CpG DNA + NIR; \#\# P $<0.01$ compared with SWCNT/GpC DNA +NIR; \#\#\# P $<0.001$ 
1 compared with NT and NIR laser - only; * $\mathrm{P}<0.05$ compared with SWCNT/GpC DNA +NIR;

$2 * * \mathrm{P}<0.01$ compared with NIR laser - only; *** $\mathrm{P}<0.001$ compared with NT. Each value

3 represents the mean + S. D. $(n=6)$. Results are representative of more than three experiments. 
a

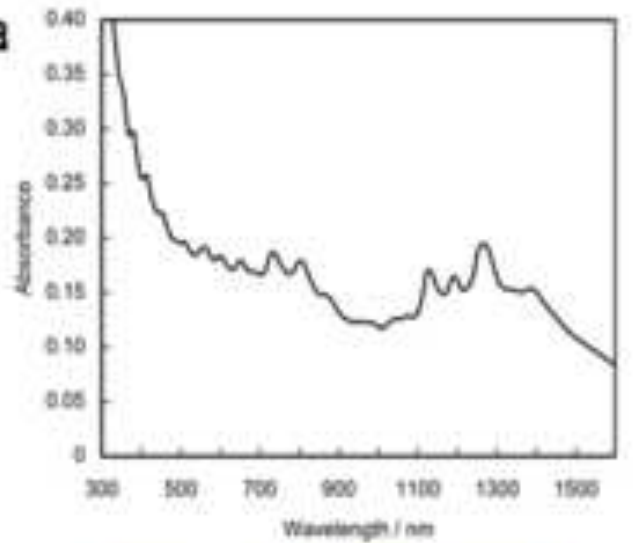

b

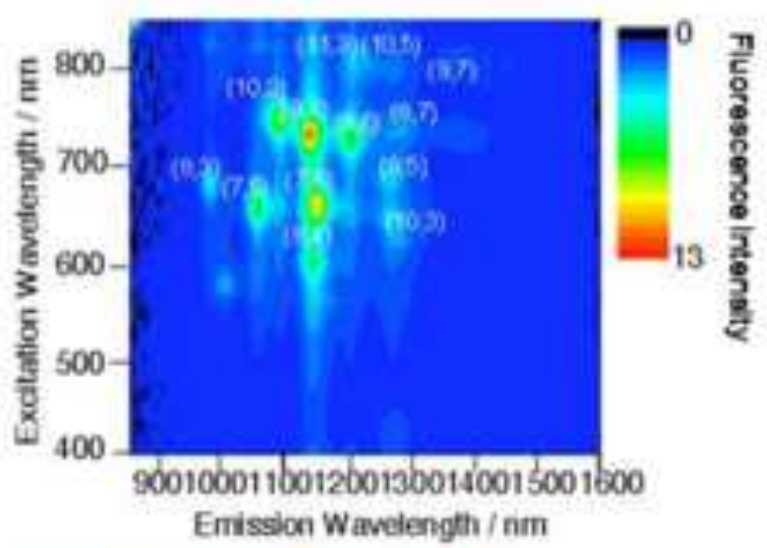

C
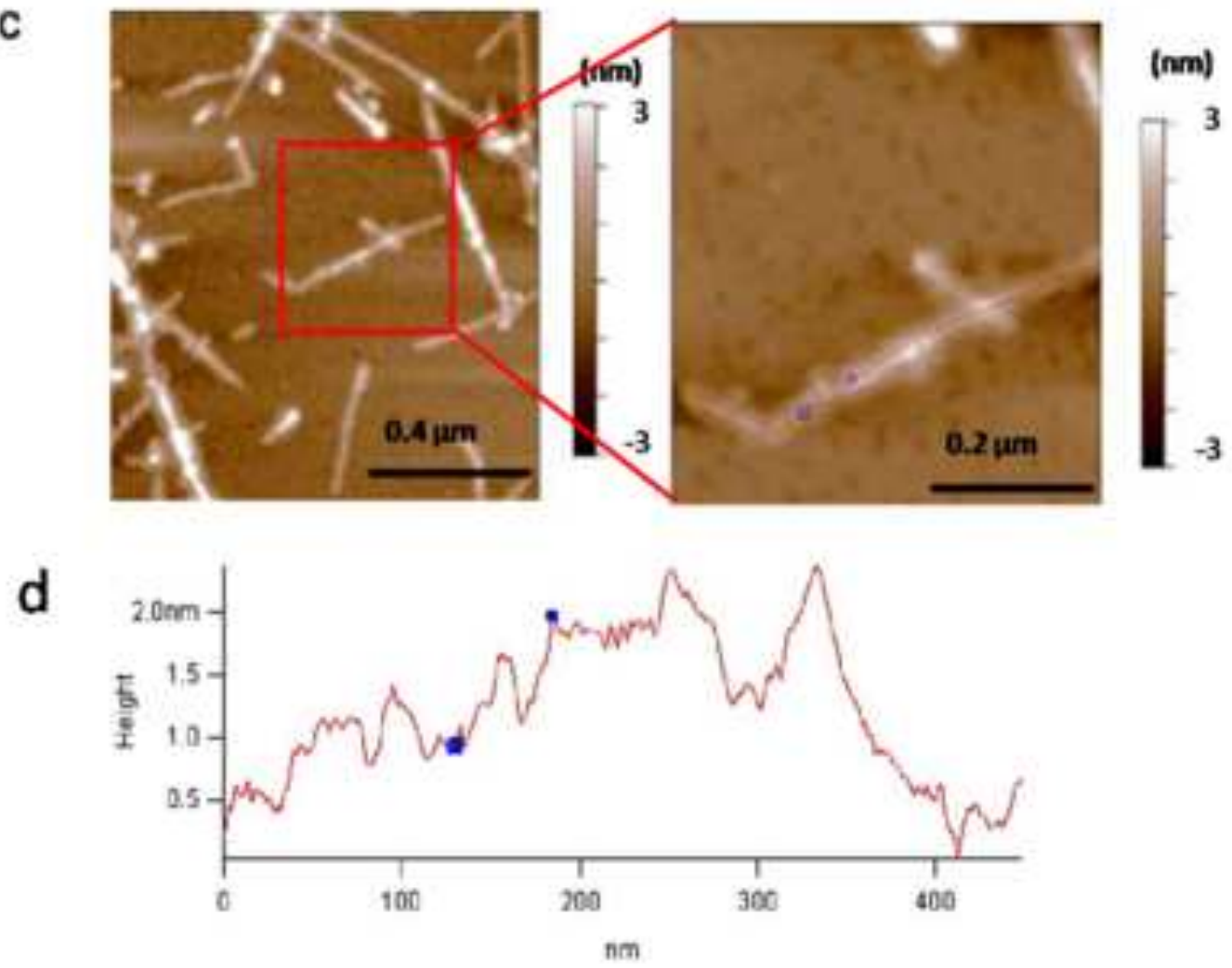

3 $-3$ 


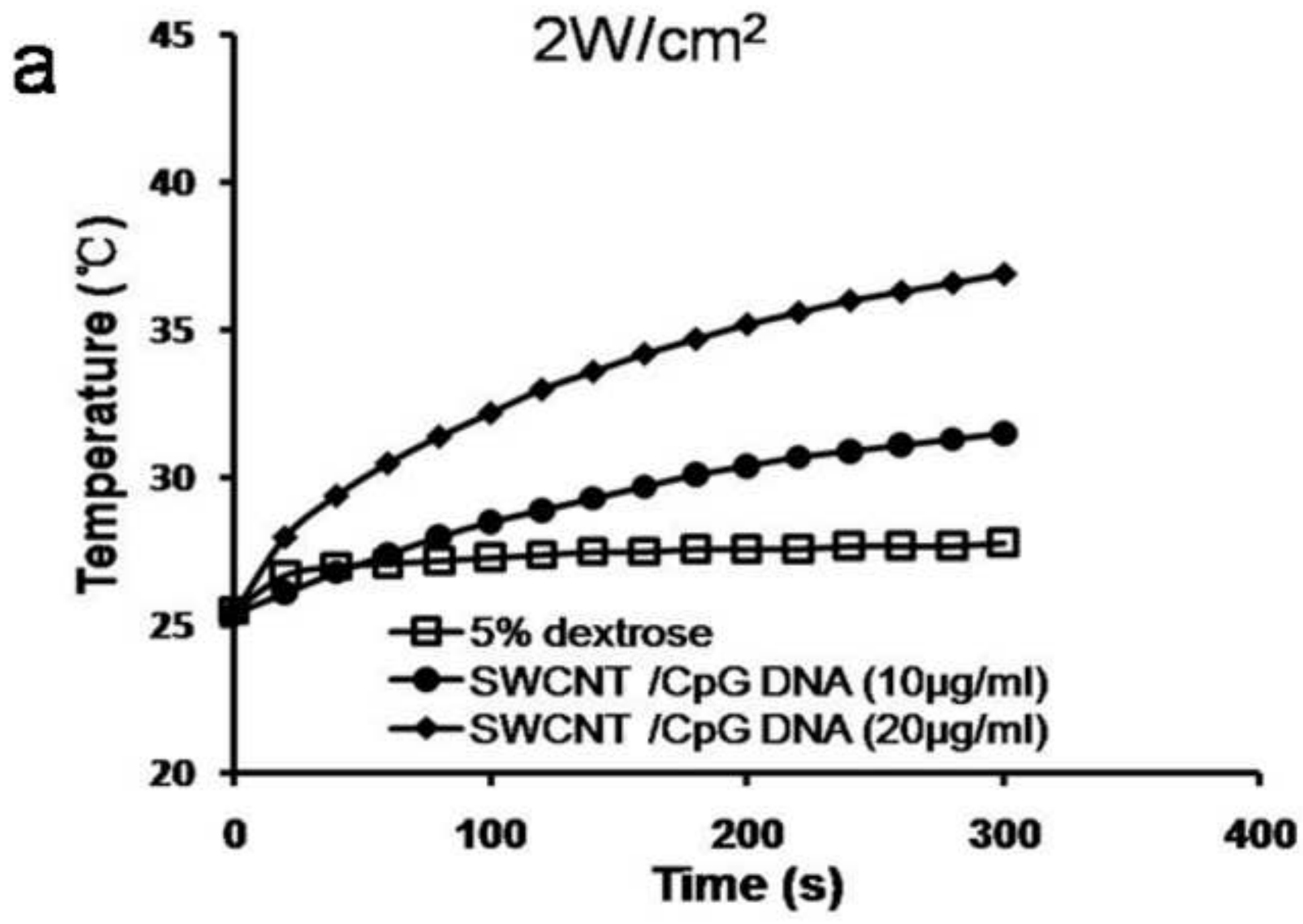




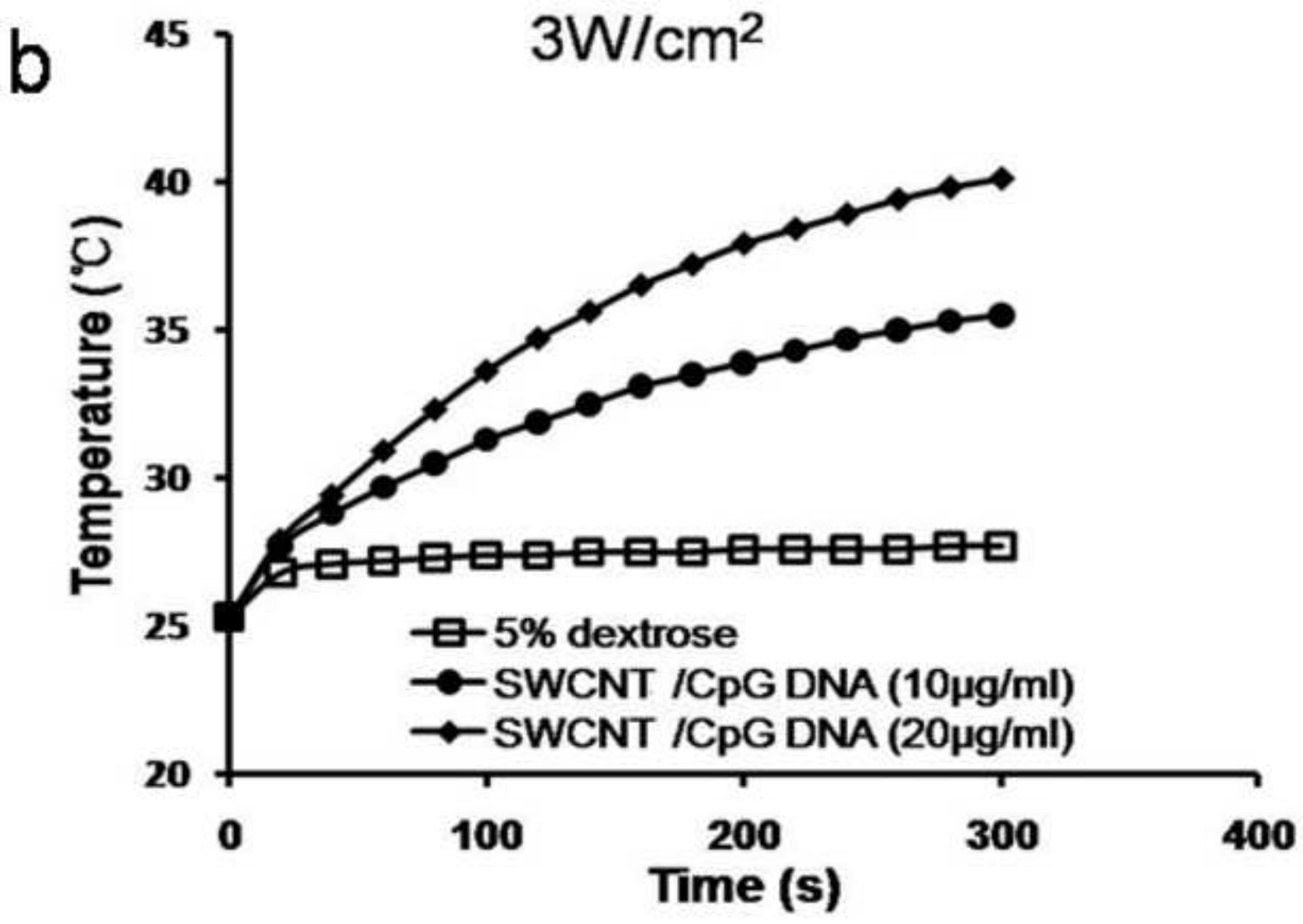




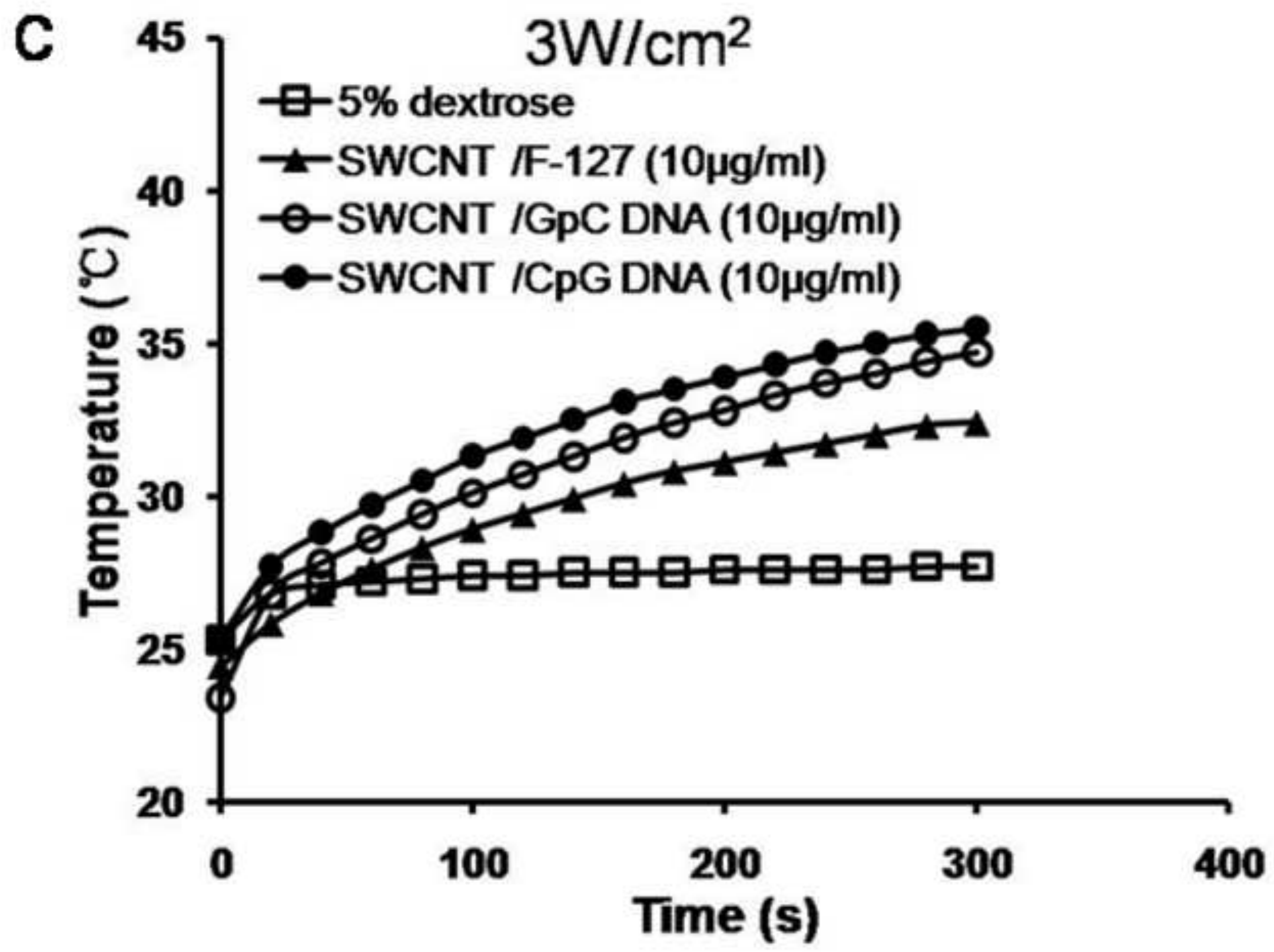



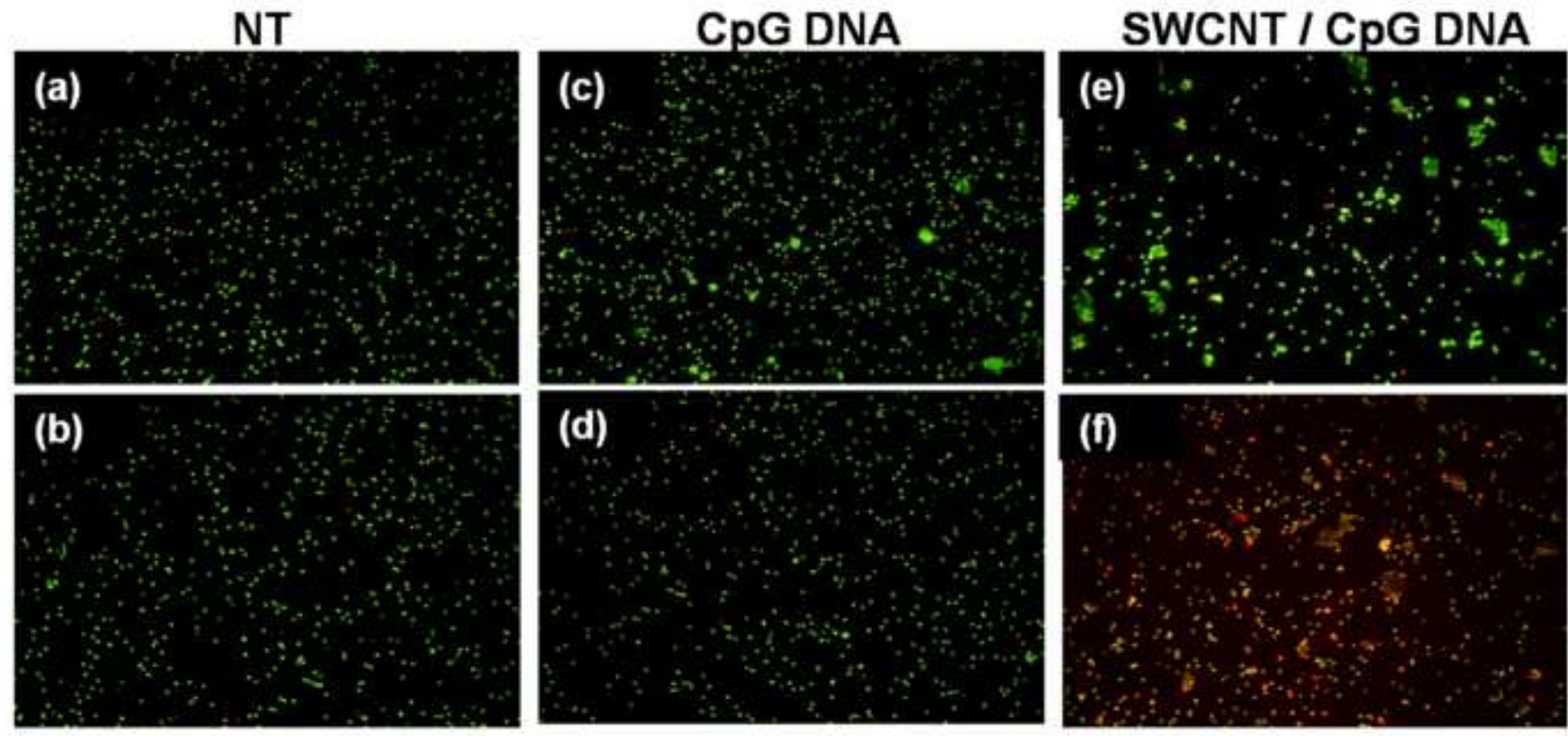


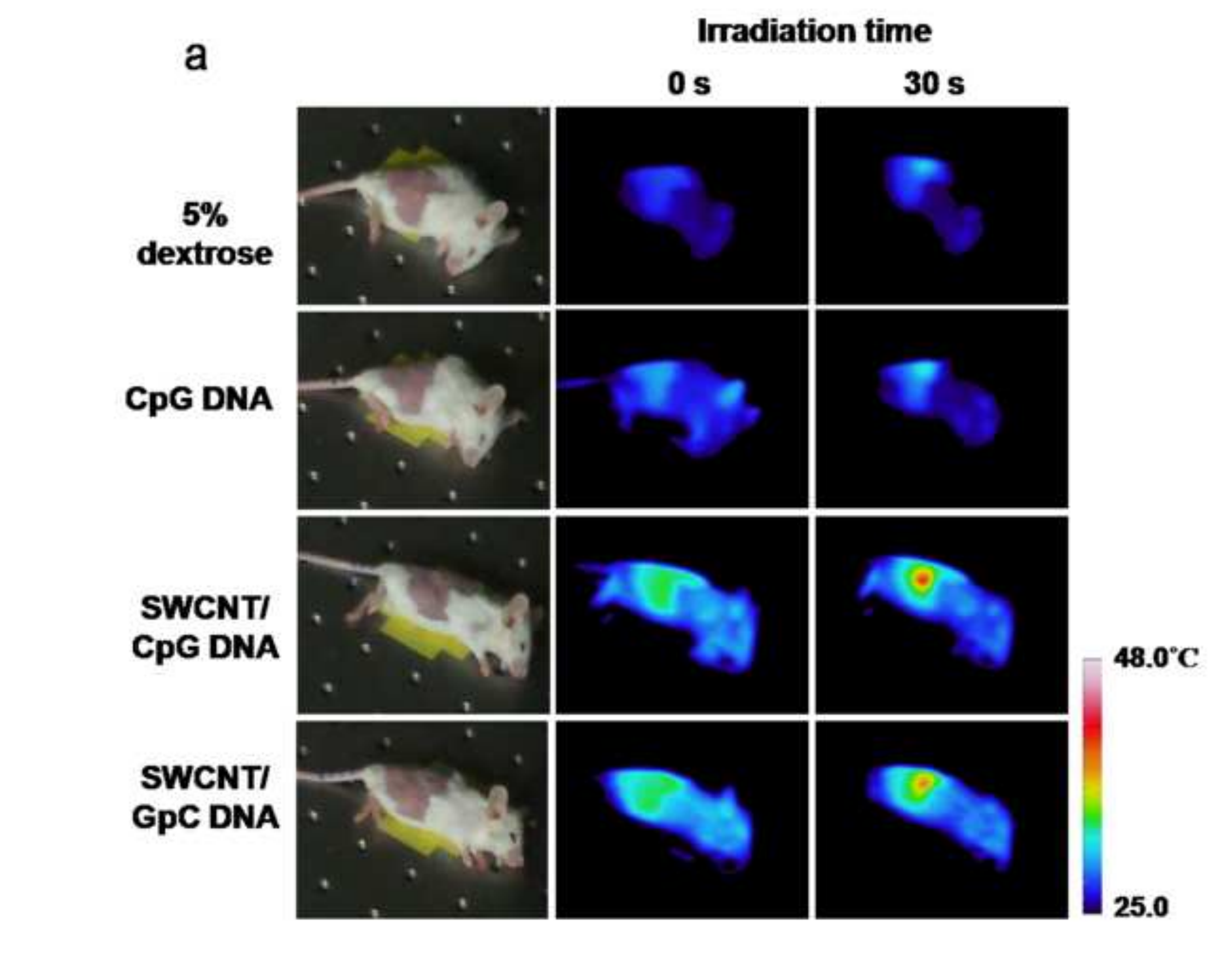

(2)

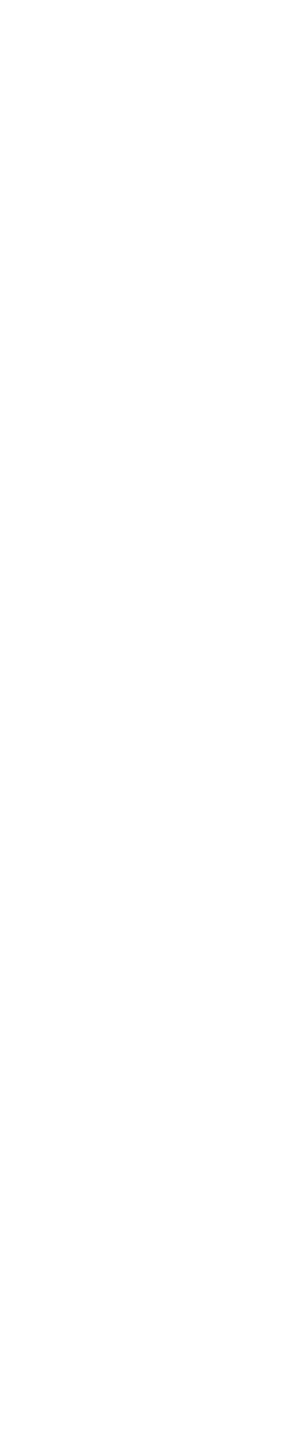

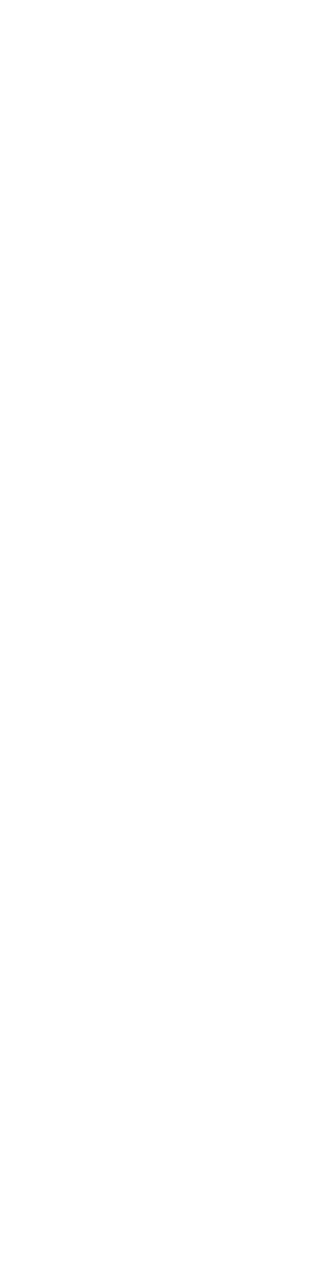

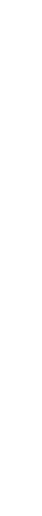




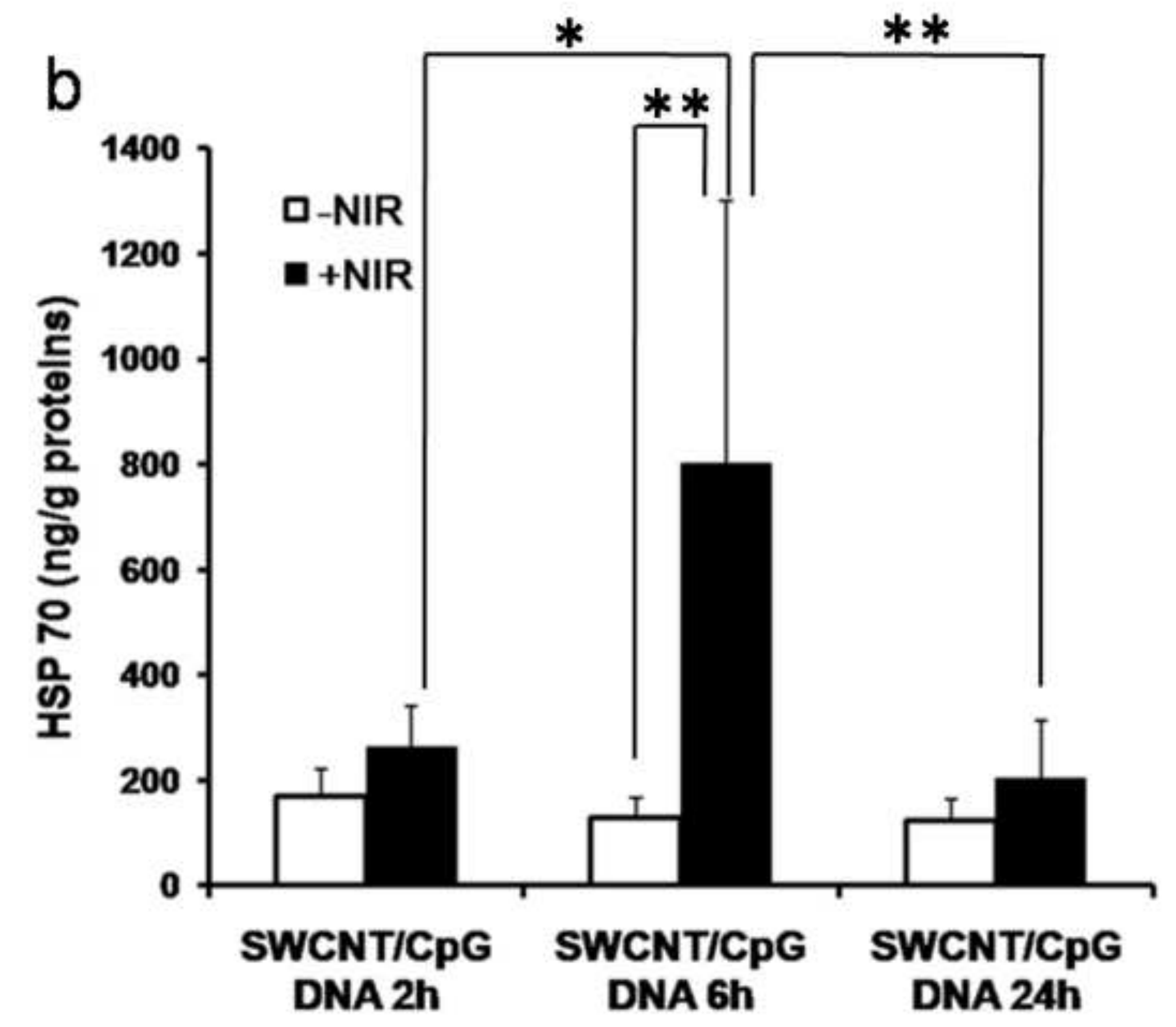

Figure(s)
Click here to download high resolution image 


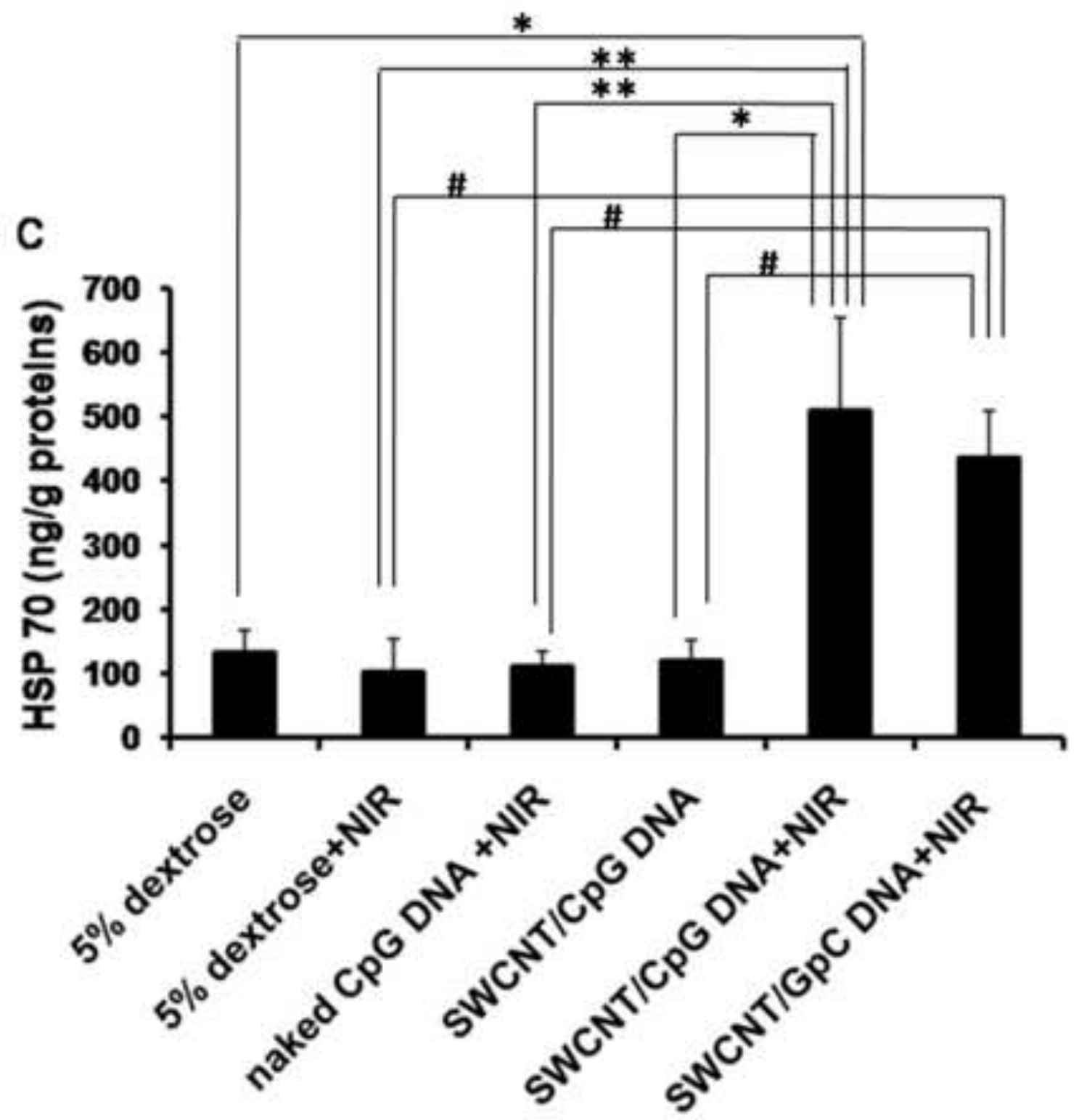




\section{Tumor}

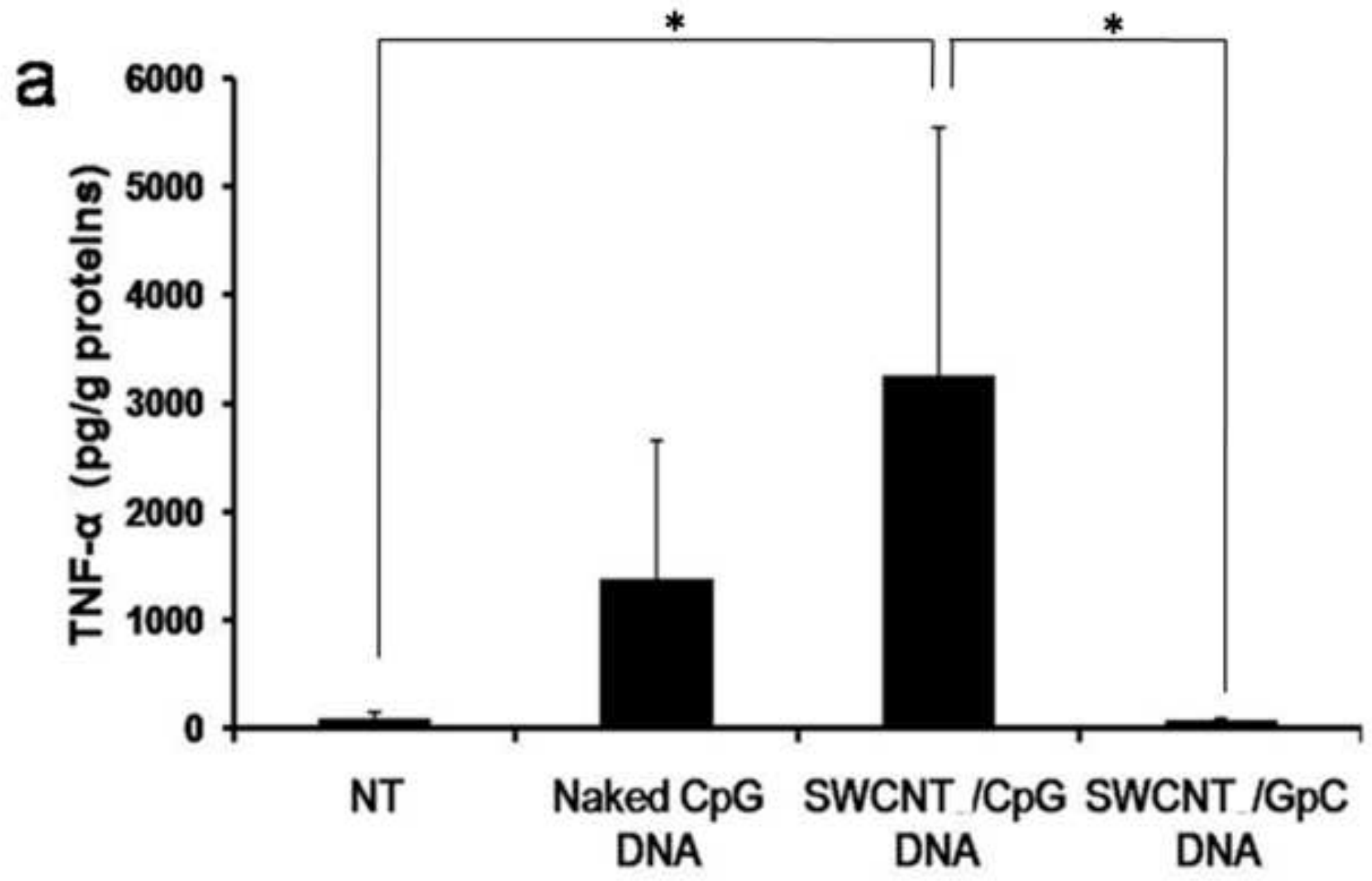


Tumor

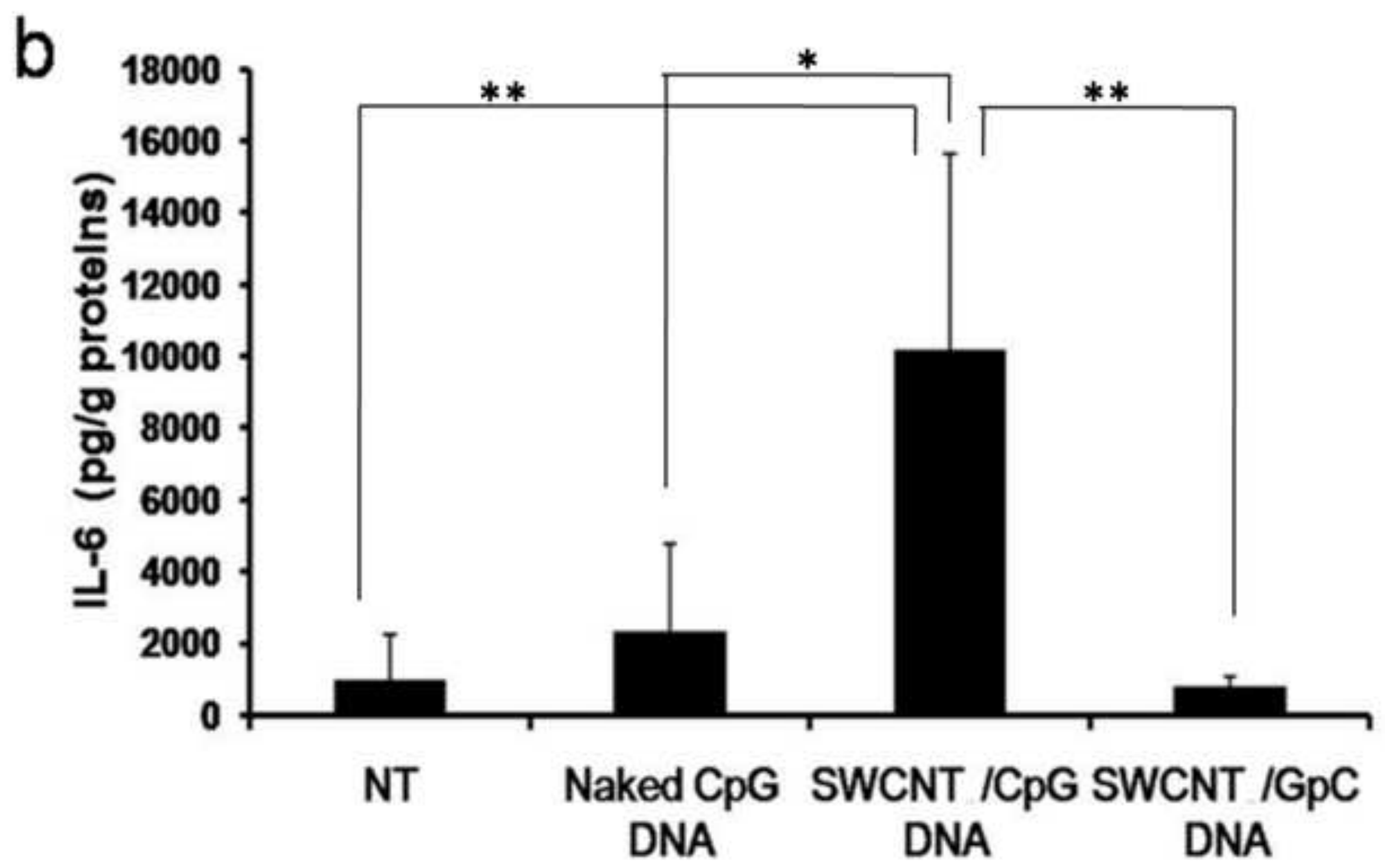




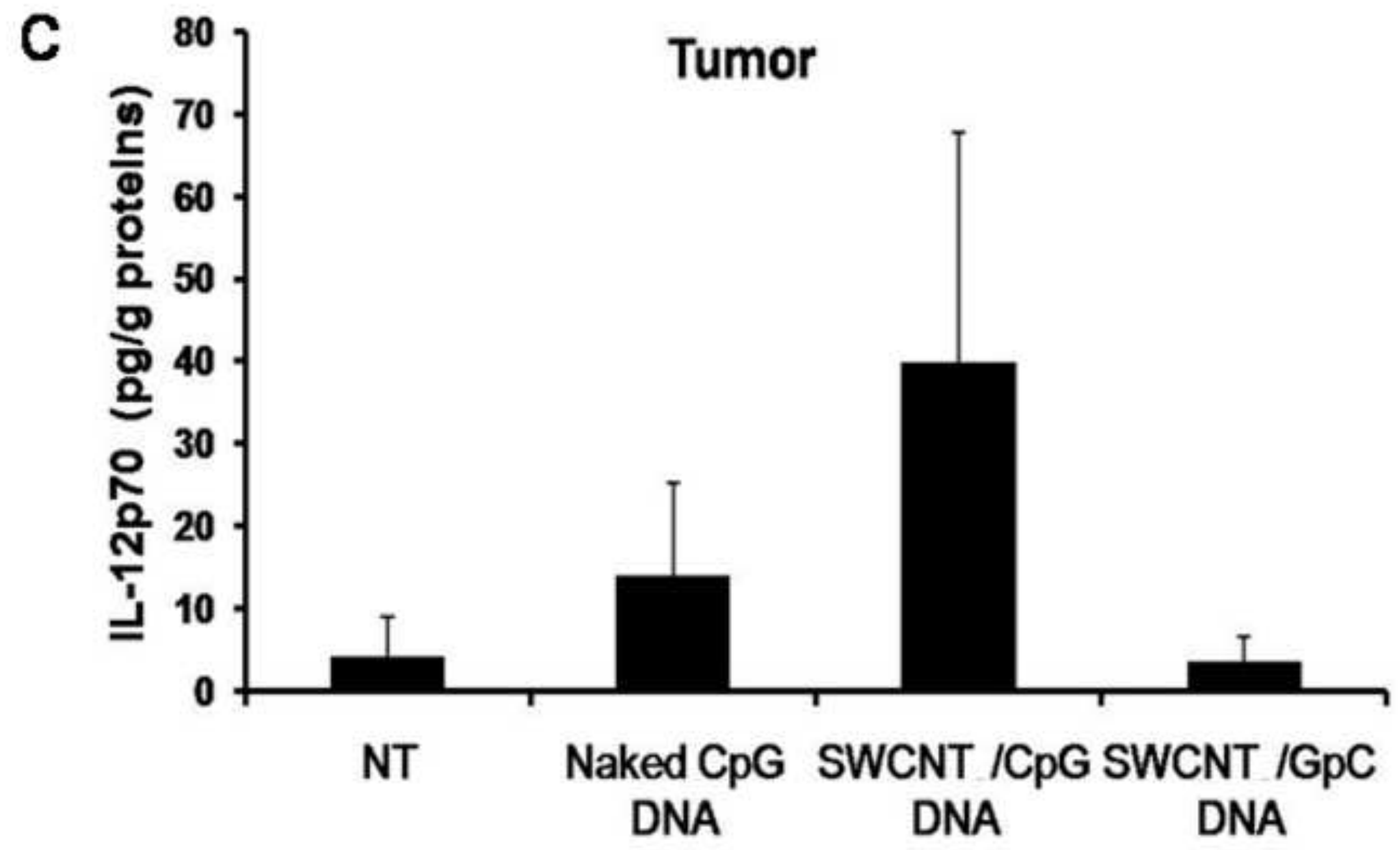




\section{Serum}

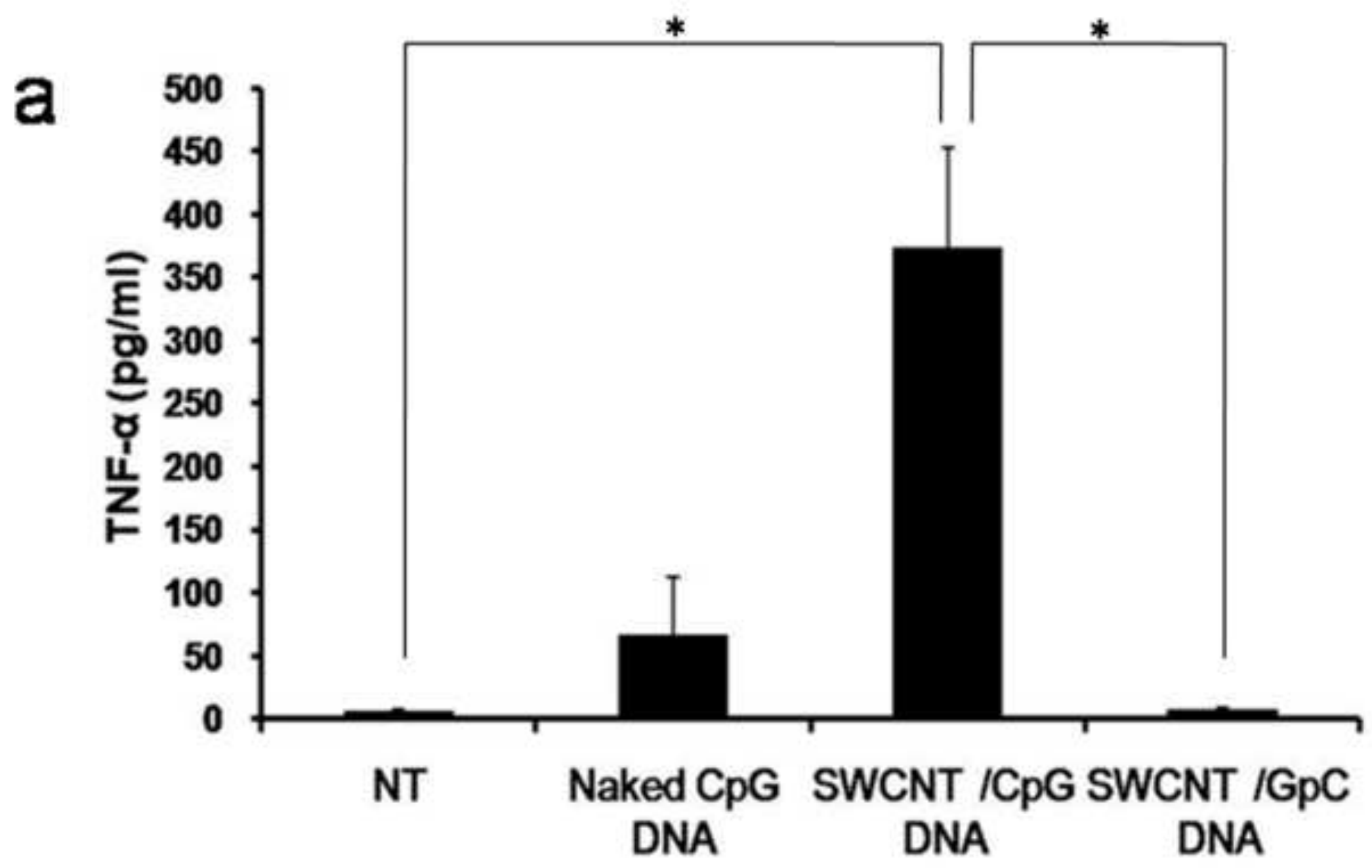




\section{Serum}

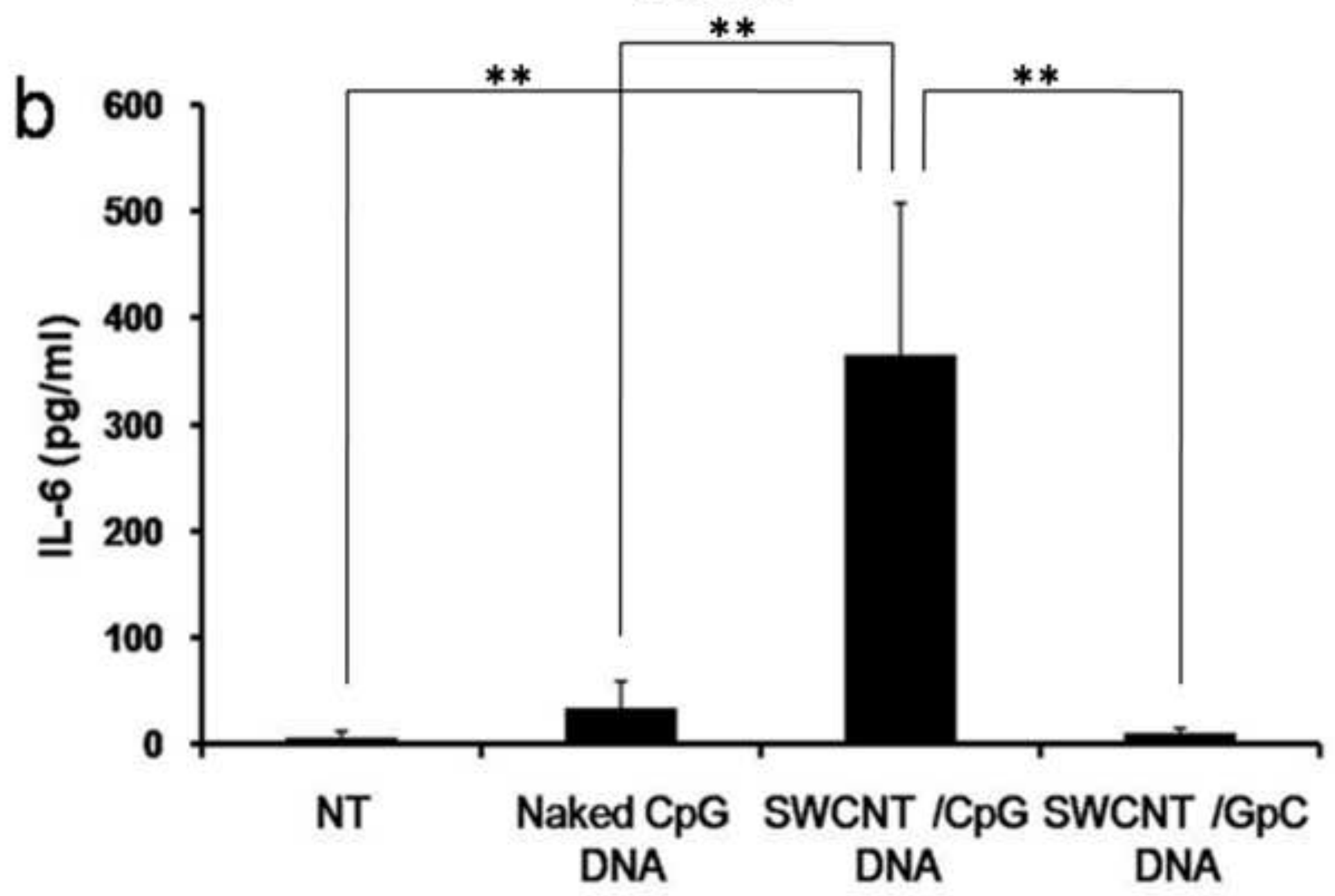




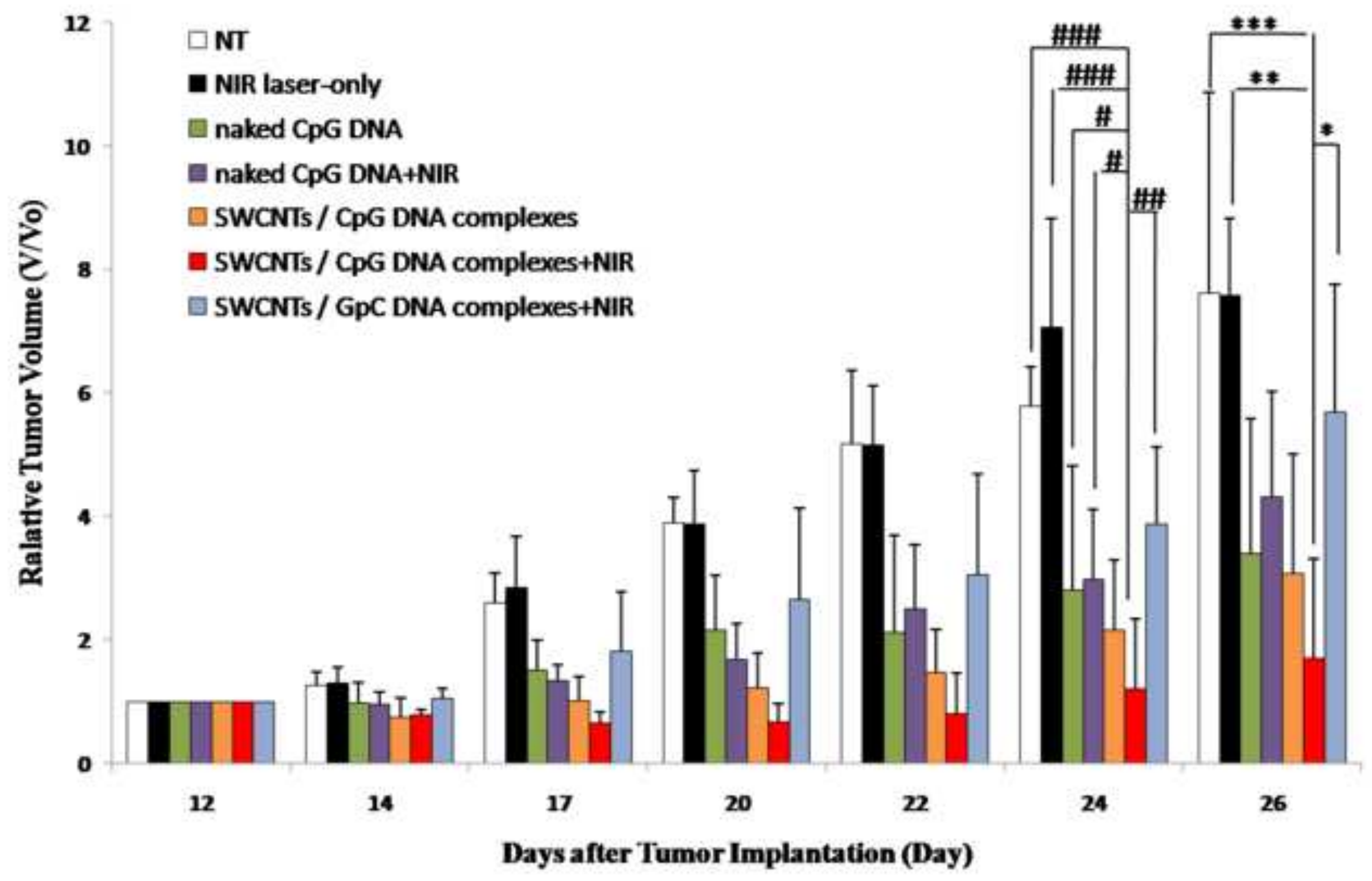

